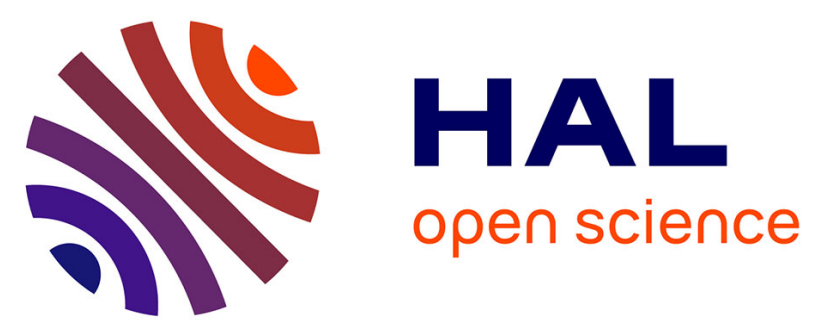

\title{
Overview of mass transfer enhancement factor determination for acidic and basic compounds absorption in water
}

Pierre-François Biard, Annabelle Couvert

\section{- To cite this version:}

Pierre-François Biard, Annabelle Couvert. Overview of mass transfer enhancement factor determination for acidic and basic compounds absorption in water. Chemical Engineering Journal, 2013, 222, pp.444-453. 10.1016/j.cej.2013.02.071 . hal-00904227

HAL Id: hal-00904227

https://hal-univ-rennes1.archives-ouvertes.fr/hal-00904227

Submitted on 14 Nov 2013

HAL is a multi-disciplinary open access archive for the deposit and dissemination of scientific research documents, whether they are published or not. The documents may come from teaching and research institutions in France or abroad, or from public or private research centers.
L'archive ouverte pluridisciplinaire HAL, est destinée au dépôt et à la diffusion de documents scientifiques de niveau recherche, publiés ou non, émanant des établissements d'enseignement et de recherche français ou étrangers, des laboratoires publics ou privés. 


\section{Overview of mass transfer enhancement factor determination for acidic and basic compounds absorption in water}

Pierre-François BIARD ${ }^{\mathrm{a}, \mathrm{b}, \mathrm{c}^{*}}$, Annabelle COUVERT ${ }^{\mathrm{a}, \mathrm{c}}$

aÉcole Nationale Supérieure de Chimie de Rennes, CNRS, UMR 6226, Avenue du Général Leclerc, CS 50837, 35708 Rennes Cedex 7, France

bUniversité de Rennes 1, CNRS, UMR 6226, 3 rue du Clos-Courtel, BP 90433, 35704 Rennes Cedex 7, France

'Université européenne de Bretagne, 5 boulevard Laënnec, 35000 Rennes, France

\section{Keywords}

Absorption; mass transfer; enhancement factor; acid; base; reversible reaction

\section{Abstract}

Absorption or gas-liquid mass transfer is a fundamental unit operation useful in many fields, particularly gas treatment (wet scrubbing). Absorption of basic or acidic compounds, even hydrophobic, in water can be achieved successfully due to the mass transfer enhancement linked to proton transfer reactions in the liquid film. The absorption rate takes this phenomenon into account through the enhancement factor $E$, which depends on many parameters: nature (irreversible or reversible), kinetics and stoichiometry of the reaction, reagents and products diffusion coefficients and concentrations. This article gives an overview of the enhancement factor determination for acidic and basic compounds transfer in water. Modeling is performed for three compounds of interest, hydrogen sulfide $\mathrm{H}_{2} \mathrm{~S}$, methyl mercaptan $\mathrm{CH}_{3} \mathrm{SH}$ and ammonia $\mathrm{NH}_{3}$, for different scenarii to assess the influence of the $\mathrm{pH}$. The results demonstrate that recombination with $\mathrm{HO}^{-}$and protonation reactions are respectively the two preponderant reactions for respectively acidic and basic compounds. They enable to reach large values of the enhancement factor at appropriated $\mathrm{pH}$ and to reduce the mass transfer resistance in the liquid film. Furthermore, the simulations highlight that, in many cases, knowledge of the reaction kinetics is not necessary since the reaction can be considered as instantaneous compared to mass transfer. 


\section{Introduction}

Absorption or gas-liquid mass transfer is widely used in environmental engineering for pollutant removal [1-4]. This unit operation involves pollutant transfer from the gas phase to a liquid phase and is performed in a gas-liquid contactor dedicated to provide a large interfacial area [5]. The key factor influencing the operation efficiency is the compound solubility in the liquid phase. For obvious cost issues, water is the main selected liquid phase even if organic solvent could be used for hydrophobic compounds treatment.

For acidic and basic compounds, even when they have a hydrophobic tendency, water could be a suitable scrubbing liquid since the absorption rate can be significantly increased by two mechanisms:

- The first mechanism is the apparent solubility increasing due to the formation of the conjugated base (acid) for acidic (basic) compounds when the pH is close or higher (close or lower) than the $\mathrm{pK}_{\mathrm{A}}$ (=- $\log \mathrm{K}_{\mathrm{A}}$ with $\mathrm{K}_{\mathrm{A}}$ the acid dissociation constant). This mechanism enables to increase the concentration gradient between the interface and the bulk which is the mass transfer driving force.

- The second mechanism is the mass transfer enhancement due to the proton transfer reaction in the liquid film located at the interface vicinity. It increases the absorption rate in the liquid film, i.e decreases the mass transfer resistance. By this way, all the resistance could be located in the gas phase.

Consequently, adding an acid $\left(\mathrm{H}_{2} \mathrm{SO}_{4}\right.$ for example) or sodium hydroxide $(\mathrm{NaOH})$ to the scrubbing water to set an appropriated $\mathrm{pH}$, it becomes possible to reach very good removal efficiencies even for hydrophobic compounds. This is typically the case for hydrogen sulfide $\left(\mathrm{H}_{2} \mathrm{~S}\right)$ [6]. The mass transfer enhancement factor, E, must be quantified to determine the absorption rate of the gas phase reactant and to achieve a proper scrubber design [7-11]. Enhancement factor quantification could be easily achieved for the film theory when considering one irreversible bimolecular reaction using an approximated but relevant analytical equation $[12,13]$. For a reversible reaction which is obviously the case of acid base reactions in water, its quantification is more complex. It depends on several parameters such as forward and reverse reaction kinetics (and the equilibrium constant of the reaction which is the ratio of them) which are often unknown, reaction stoichiometry, products and reagents bulk concentrations and diffusion coefficients. Simple analytical solutions could be obtained for a few special cases only [14]. The problem can be significantly simplified assuming that the reaction kinetics is not the limiting step and that equilibrium prevails everywhere in the liquid film (instantaneous reaction). Several authors developed analytical equations for different reaction 
stoichiometries with this assumption [15,16]. Astarita and Savage [17] proposed a method which is applicable to any reversible reaction with the same hypothesis, based on the determination of the extent of reaction by a simple numerical resolution. Since reversible proton transfer reactions are very fast (diffusion controlled specifically) [18], forward and reverse reaction kinetic constants are usually poorly known. They are often considered as "instantaneous" by chemists. However, even if the reaction is very fast, its rate could not be instantaneous compared to the mass transfer rate and drives many authors to erroneous results. Onda et al. (1970) developed an approximated solution for the general case using the linearization method proposed by Hikita and Asai (1964) to simplify the reaction rate $[19,20]$. Another approach, developed by Kenig and his coworkers, is to solve directly a multicomponent two-zone advection-diffusion-reaction model using a Maxwell-Stefan formulation of the problem [21-25].

In addition to the intrinsic complexity of the mathematical resolution of the problem to determine $\mathrm{E}$, many supplementary difficulties could be highlighted for the case of acidic or basic compounds absorption:

- Several reactions can happen simultaneously in the liquid film. For example, in pure water, two reactions can be observed for an acid: dissociation and/or recombination with $\mathrm{HO}^{-}$. A basic compound can react with a proton or with $\mathrm{H}_{2} \mathrm{O}$ directly. The enhancement factor determination is even more complicated in the case of parallel reactions. A simple solution could be obtained only if the reactions are pseudo-first order or instantaneous compared to the absorption rate and if they are independent [26-28];

- In natural water, "parasite" reactions are possible, especially with the alkaline species $\left(\mathrm{H}_{2} \mathrm{CO}_{3}\right.$, $\mathrm{HCO}_{3}{ }^{-}, \mathrm{CO}_{3}{ }^{2-}$ ) and can improve the enhancement factor;

- Reagents and products diffusion coefficients are required for the enhancement quantification. The experimental determination of the diffusion coefficients in the gas (Winkelmann method) and the liquid phases (two cells system) remains the most accurate technique $[29,30]$. The alternative way is to use semi-empirical correlations (Wilke-Chang, Hayduk-Laudie, Fuller-Schettler-Giddings, etc.) widely commented in the literature $[5,29]$. However, calculation of diffusion coefficients in a liquid phase can present a relatively large uncertainty [5]. For low solute content, this calculation is done considering an infinite dilution. To simplify the resolution, it is convenient to assume that the diffusion coefficients are constant in the liquid film [15]. For free ions $\left(\mathrm{H}^{+}\right.$or $\mathrm{HO}^{-}$for example) and electrolytes $\left(\mathrm{NaOH}, \mathrm{H}_{2} \mathrm{SO}_{4}\right.$, etc.), diffusion coefficients calculation is related to ions conductivity [31]. However, depending on the conditions (pure water or water containing salt), the ions diffusion coefficients must be calculated considering the free ions or not $[15,32]$. This aspect is discussed deeper in the section 3.1 . 
- For electrolyte solutions, the electric potential can have an influence on the ion diffusion. Glasscock and Rochelle implemented the Nernst-Planck equation to take this electric potential into account [33]. They calculated the electric potential using the Henderson equation. Littel et al. also studied the influence of ionic species on the absorption rates [34]. As reported by Van Swaaij et al., they concluded that compared to the absorption models in which electroneutrality was assured by means of equal diffusivities of the ionic species, the deviation was negligible [7].

- Unless the liquid phase is perfectly mixed (which is usually not the case of gas scrubbers), the liquid composition and $\mathrm{pH}$ vary from the inlet to the outlet of the gas-liquid contactor and the enhancement factor determination must be achieved for infinitesimal volume elements, which can lead to heavy numerical resolutions. It confirms the need of simple procedure to calculate the enhancement factor.

- The exothermicity of the reactions can be neglected since the transfer of several g. $\mathrm{m}^{-3}$ of acidic or basic compounds are necessary to increase the water temperature of only $1 \mathrm{~K}$ considering a classical liquid-to-gas mass flow rates ratio of 3 and enthalpies of reaction in the order of magnitude of $10^{2} \mathrm{~kJ} \cdot \mathrm{mol}^{-1}$.

To our knowledge, a few article in the literature focuses on the mass transfer enhancement factor determination for acid-base reactions in water depending on the $\mathrm{pH}$. Sometimes, the determination is done assuming that the reaction is irreversible and instantaneous which can lead to overestimations of the enhancement factor [35]. The aim of this article is to give an overview of enhancement factor determination for acidic and basic compounds transfer in water trying to give a better understanding of the process. The development is based on the two films theory which has proven for several decades very good numerical calculations of the absorption rate for many cases and which is still used by both engineers and researchers (academicians and industries). Three pollutants of interest will be particularly studied: $\mathrm{NH}_{3}, \mathrm{H}_{2} \mathrm{~S}$ and $\mathrm{CH}_{3} \mathrm{SH}$. The article provides guidelines to select the $\mathrm{pH}$ of the scrubbing liquid and if necessary to choose the good assumptions for simplifications. A pertinent $\mathrm{pH}$ selection is very important since a compromise is required between a large mass transfer enhancement (which naturally will require extreme $\mathrm{pH}$ ) and the need to limit the operating costs (which will be affected by extreme $\mathrm{pH}$ due to reagents consumption and parasite reactions such as carbon dioxide absorption at alkaline $\mathrm{pH}$ ). 


\section{Mass transfer enhancement factor determination}

\subsection{Mass transfer rate}

Gas-liquid mass transfer can be described according to various theories. Usually, the steady state two- film theory is applied. At a given location of the reactor, the molar flux per square meter of gasliquid interface, for a gas phase reactant $A$ transferred into a liquid (dJ in mol. $\mathrm{m}^{-2} \cdot \mathrm{s}^{-1}$ ) in which a reaction takes place, is [5]:

$d J=E k_{L}\left(C_{A}^{*}-C_{A}\right)=K_{L}\left(C_{A}^{E q}-C_{A}\right)$ Eq. 1

$\mathrm{E}$ is the so-called enhancement factor (dimensionless) which is the ratio of the absorption rate with and without the reaction for the same difference $C_{A}^{*}-C_{A} \cdot C_{A}$ is the pollutant concentration in the bulk $\left(\right.$ mol.m $\mathrm{m}^{-3}$ or mol. $\left.\mathrm{L}^{-1}\right) . \mathrm{C}_{\mathrm{A}}^{*}$ is the liquid pollutant concentration at the gas-liquid interface. $\mathrm{C}_{\mathrm{A}}^{\mathrm{Eq}}$ is the liquid pollutant concentration in equilibrium with the gas phase concentration:

$$
C_{A}^{E q}=\frac{p_{A}}{H_{A}}=\frac{R T C_{A}^{G}}{H_{A}}
$$

$\mathrm{p}_{A}$ is the partial pressure $(\mathrm{Pa}), \mathrm{C}_{A}^{G}$ is the gas phase concentration $\left(\mathrm{mol} . \mathrm{m}^{-3}\right), \mathrm{H}_{A}$ the Henry's law constant $\left(\mathrm{Pa} \cdot \mathrm{m}^{3} \cdot \mathrm{mol}^{-1}\right)$. The Henry's coefficient can be found in the literature, using the compilation of Sander or specific articles [36-41]. When the value cannot be found for a specific compound or in specific conditions, it remains possible to use some thermodynamic models which provide good accuracies [39,42-45]. $K_{L}$ and $K_{L}$ are respectively the local and overall liquid film mass transfer coefficient $\left(\mathrm{m} . \mathrm{s}^{-1}\right)$ linked together by the following relation:

$$
\frac{1}{K_{L}}=\frac{1}{E k_{L}}+\frac{R T}{H_{A} k_{G}}
$$

$k_{G}$ is the local gas side mass transfer coefficient. $k_{L}$ and $k_{G}$ order of magnitude are respectively 1-5 10${ }^{4} \mathrm{~m} \cdot \mathrm{s}^{-1}$ and 1-5 $10^{-2} \mathrm{~m} \cdot \mathrm{s}^{-1}$ and can be measured or determined by semi-empirical correlations for different contactors at fixed operating conditions (temperature, viscosities, densities, ionic strength, etc.) $[5,29,46]$. Eqs. 1 to 3 enable to write:

$$
C_{A}^{*}=\frac{k_{G}\left(R T C_{A}^{G}-H_{A} C_{A}\right)}{H_{A} k_{G}+R T E k_{L}}+C_{A}
$$


This relation shows that $C_{A}^{*}$ depends on the local mass transfer coefficients, $C_{A}^{G}, C_{A}$ and the enhancement factor. $C_{A}^{*}$ is naturally $\geq C_{A}$. Two limit behaviors can be observed. For a poorly soluble compound (large value of $H_{A}$ ) and with a low $E$ value, $C_{A}^{*}$ tends toward $C_{A}^{E q}$. For a very soluble compound (low value of $\mathrm{H}_{A}$ ) and/or if $E$ is high (which enables to reach important removal efficiencies), if $\mathrm{C}_{\mathrm{A}}$ can be neglected:

$C_{A}^{*} \approx \frac{k_{G} C_{A}^{G}}{E k_{L}}$

Eq. 5

In this case, the absorption rate is maximal and the resistance in the liquid phase is negligible. The condition to respect is :

$R T E k_{L} \gg H_{A} k_{G} \Rightarrow \frac{E}{H_{A}} \gg \frac{k_{G}}{R T k_{L}} \approx 0.04$ assuming $\mathrm{k}_{\mathrm{L}}=10^{-4} \mathrm{~m} \cdot \mathrm{s}^{-1}$ and $\mathrm{k}_{G}=10^{-2} \mathrm{~m} \cdot \mathrm{s}^{-1}$ at $293 \mathrm{~K}$

Eq. 6

\subsection{Enhancement factor determination for reversible reactions}

\subsubsection{General case}

Depending on the amount of acid or basic salt $\left(\mathrm{H}_{2} \mathrm{SO}_{4}, \mathrm{HCl}, \mathrm{NaOH}\right.$, etc.) added to the scrubbing solution to set the $\mathrm{pH}$, the ionic strength should be taken into account when calculating the absorption rate (Eq. 1). Indeed, the ionic strength has a rather strong influence on the absorbed compound solubility (the solubility decreases when the ionic strength increases due to the salting out effect) and the liquid mass transfer resistance. However, the ionic strength has a limited influence on the enhancement factor calculation for acid and basic compounds and only at very extreme $\mathrm{pH}(\mathrm{pH}<$ 3 or $>12$ ) through the counterions concentrations whose activity coefficients can be different of one. In order to simplify, the ionic strength is neglected in this development.

The following reversible reaction is considered after absorption of the specie A in solution:

$\gamma_{A} A_{G}+\gamma_{B} B \stackrel{k_{7}}{\underset{k_{-7}}{\rightleftharpoons}} \gamma_{C} C+\gamma_{D} D \quad K=C_{C}{ }^{p} C_{D}{ }^{q} / C_{A}{ }^{m} C_{B}{ }^{n}=k_{7} / k_{-7}$

Here, $C$ and $D$ are respectively the conjugated acid or base of $A$ and $B . k_{7}$ and $k_{-7}$ are the forward and reverse kinetic constants, $K\left(k_{7} / k_{-7}\right)$ is the equilibrium constant and $m, n, p, q$ are the kinetics order of respectively $A, B, C$ and $D$. Onda et al. (1970) deduced from the material balances and the boundary conditions that [19]: 
$E=\frac{1-C_{A} / C_{A}^{*}+\frac{\gamma_{A}}{\gamma_{C}} \frac{D_{C}}{D_{A}}\left(\frac{C_{C}^{*}-C_{C}}{C_{A}^{*}}\right)}{1-C_{A} / C_{A}^{*}}=\frac{C_{A}^{*}-C_{A}+\frac{\gamma_{A}}{\gamma_{C}} \frac{D_{C}}{D_{A}}\left(C_{C}^{*}-C_{C}\right)}{C_{A}^{*}-C_{A}}$

Eq. 8

$C_{B}^{*}=C_{B}-\frac{\gamma_{B}}{\gamma_{C}} \frac{D_{C}}{D_{B}}\left(C_{C}^{*}-C_{C}\right)$

Eq. 9

$C_{D}^{*}=C_{D}+\frac{\gamma_{D}}{\gamma_{C}} \frac{D_{C}}{D_{D}}\left(C_{C}^{*}-C_{C}\right)$

$D_{i}$ and $C_{i}$ are respectively the molecular diffusion coefficient $\left(\mathrm{m}^{2} \cdot \mathrm{s}^{-1}\right)$ and the concentration (mol. $\mathrm{L}^{-1}$ ) of any compound $i$. The subscripts * refers to the interface. The concentration should be used in mol. $L^{-1}$.

For any problem to solve, 4 parameters are unknown $\left(C_{B}^{*}, C_{C}^{*}, C_{D}^{*}\right.$ and $\left.E\right)$ for three equations. Therefore, another equation is required. Onda et al. (1970) proposed an approximated solution of $E$ obtained by linearization of the material balance differential equation of the compound A [19]. With the assumption that the equilibrium prevails at the interface; if $m=p=1$ (case of proton transfer reactions [18]), this approximated solution is:

$$
E=\frac{1+\frac{\gamma_{A}}{\gamma_{C}} \frac{D_{C}}{D_{A}} \frac{K C_{B}^{* n}}{C_{D}^{*} q}+\frac{\gamma_{A}}{\gamma_{C}} \frac{D_{C}}{D_{A}}\left(\frac{K C_{B}^{* n}}{C_{D}^{*} q} C_{A}-C_{C}\right) \frac{1-1 / \cosh \left(\sqrt{M_{2}}\right)}{C_{A}^{*}-C_{A}}}{1+\frac{\gamma_{A}}{\gamma_{C}} \frac{D_{C}}{D_{A}} \frac{K C_{B}^{* n}}{C_{D}^{* a}} \frac{\tanh \left(\sqrt{M_{2}}\right)}{\sqrt{M_{2}}}}
$$

With $M_{2}$ a dimensionless number (familiar with the Hatta number):

$$
M_{2}=\frac{\gamma_{A} D_{A} k_{7} C_{B}^{* n}}{k_{L}^{2}}\left(1+\frac{\gamma_{C}}{\gamma_{A}} \frac{D_{A}}{D_{C}} \frac{C_{D}^{* q}}{K C_{B}^{* n}}\right)
$$

When $\gamma_{C}$ or $\gamma_{D}$ are equal to 0 (one reagent or one product), $\mathrm{n}$ and q must be respectively replaced by 0 in Eqs. 11 and 12 since proton transfer reactions are elementary reactions. Versteeg et al. (1989) demonstrated that the approximated equation 11 is valid and provide a good estimation of $E$ with a deviation lower than $2 \%$, only if one product is formed $\left(\gamma_{D}=0\right)$ or if $m=p$ (which is considered here) $[14]$.

For acidic or basic compounds, $C_{A}$ and $C_{C}\left(C_{B}\right.$ and $\left.C_{D}\right)$ can be deduced from the total concentrations in solution (noted $C_{A}^{\text {Total }}=C_{A}+C_{C}$ and $C_{B}^{\text {Total }}=C_{B}+C_{D}$ ) for an infinitesimal volume element (or the whole 
reactor for a continuous stirred tank reactor). The $\mathrm{pH}$ and the $\mathrm{pK}_{\mathrm{A}}$ of each couple (Table 1) are required. Therefore, $E$ can be determined for a given value of $C_{A}^{*}$ :

- Knowing $\mathrm{C}_{\mathrm{A}}^{\text {Total }}$ and $\mathrm{C}_{\mathrm{B}}^{\text {Total }}$, the $\mathrm{pH}$, the $\mathrm{pK}_{\mathrm{A}}$, the diffusion coefficients, the reverse or forward kinetics constant, the stoichiometric coefficients and the liquid film coefficient $\mathrm{k}_{\mathrm{L}}$;

- By using a solver (for example the Solver Excel ${ }^{\circledR}$ ) to solve the set of Eqs. 8 to 11 following the procedure presented Fig. 1.

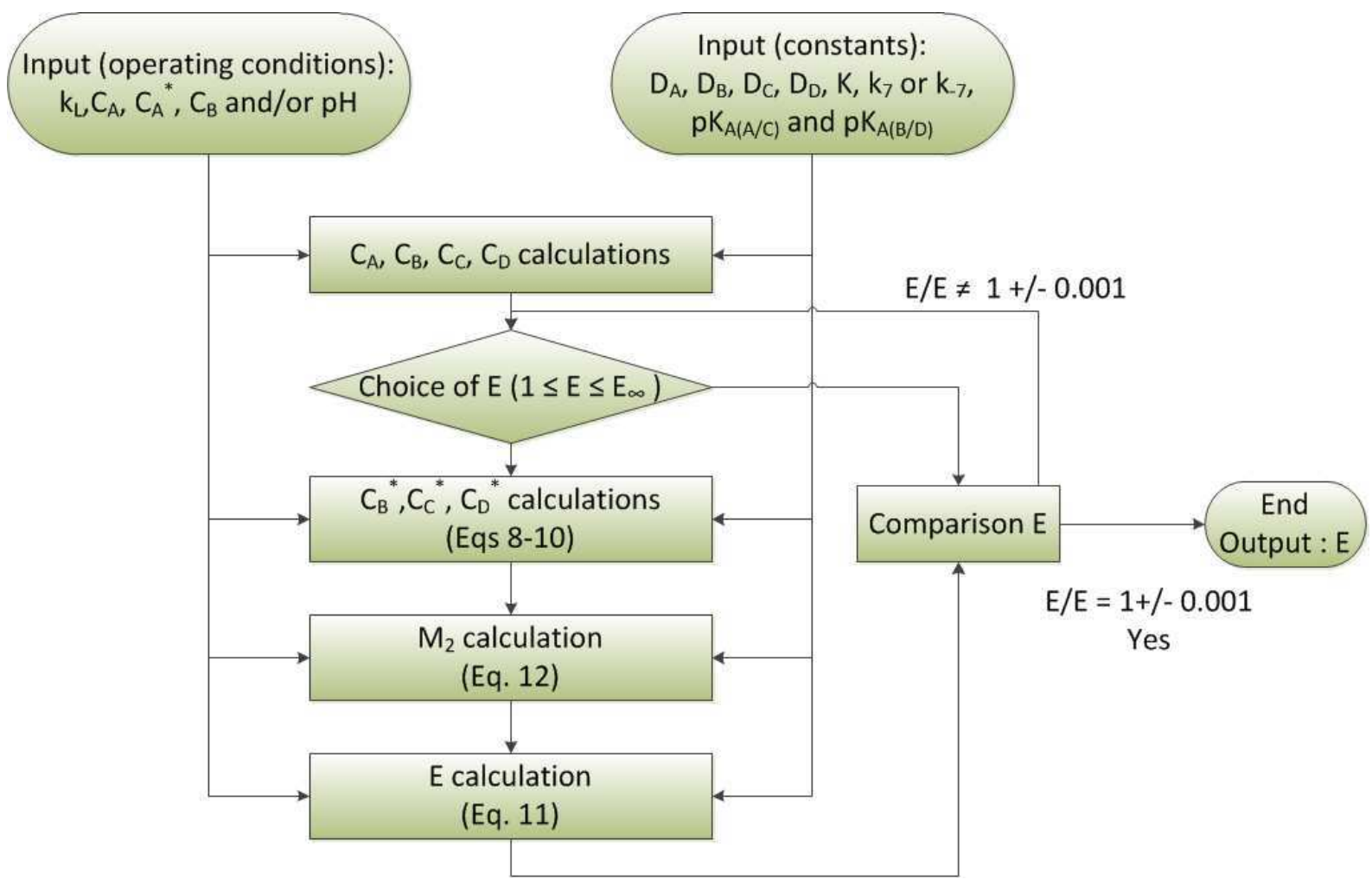

Figure 1 : Numerical resolution procedure.

Astarita et al. (1980) developed an alternative method which can be used for any kind of reversible reactions considered as instantaneous [17]. They assumed that the kinetics of reaction is so fast that the chemical equilibrium must prevail everywhere in the liquid phase. If we note $\xi$ the extent of reaction in the liquid film, they demonstrated for a reaction as presented by Eq. 7 that:

$$
\begin{aligned}
& \xi=\left(E_{\infty}-1\right)\left(C_{A}^{*}-C_{A}\right) \Rightarrow E_{\infty}=1+\xi /\left(C_{A}^{*}-C_{A}\right) \\
& \frac{C_{A}^{*}}{C_{A}}=\left(1-\frac{\gamma_{B} D_{A} \xi}{D_{B} C_{B}}\right)^{-1}\left(1+\frac{\gamma_{C} D_{A} \xi}{D_{C} C_{C}}\right)\left(1+\frac{\gamma_{D} D_{A} \xi}{D_{D} C_{D}}\right)
\end{aligned}
$$

Eq. 14 is a polynomial equation for $\xi$ and could have more than one root. However, only one root will make the ratio $C_{A}^{*} / C_{A}>1$ (for absorption) and will enable to determine the enhancement factor $E_{\infty}$ 
for an instantaneous reaction. A numerical resolution is required to solve Eqs. 13 and 14 in the general case. However, for all the cases considered in this study $\left(\gamma_{B}\right.$ and $\gamma_{D}=0$ or 1$)$, an analytical equation can be derived.

\subsubsection{Particular case of a acid-base pairs reaction: $\gamma_{A}=\gamma_{B}=\gamma_{C}=\gamma_{D}=1$}

In this case, Eqs. 11 and 12 can be slightly simplified:

$$
E=\frac{1+\frac{D_{C}}{D_{A}} \frac{K C_{B}^{*}}{C_{D}^{*}}+\frac{D_{C}}{D_{A}}\left(\frac{K C_{B}^{*}}{C_{D}^{*}} C_{A}-C_{C}\right) \frac{1-1 / \cosh \left(\sqrt{M_{2}}\right)}{C_{A}^{*}-C_{A}}}{1+\frac{D_{C}}{D_{A}} \frac{K C_{B}^{*}}{C_{D}^{*}} \frac{\tanh \left(\sqrt{M_{2}}\right)}{\sqrt{M_{2}}}} \text { with } \mathrm{M}_{2}=\frac{D_{A} k_{7}}{k_{L}^{2}}\left(C_{B}^{*}+\frac{D_{A}}{D_{C}} \frac{C_{D}^{*}}{K}\right)
$$

For an instantaneous reaction, $\mathrm{M}_{2}$ is so large that an analytical solution can be deduced to determine $E_{\infty}$ from Eqs. 8 to 12 :

$E_{\infty}=1+\frac{D_{C}}{2 D_{A}\left(C_{A}^{*}-C_{A}\right)}\left(\sqrt{\left(\frac{D_{D}}{D_{C}} C_{D}+\frac{D_{D}}{D_{B}} K C_{A}^{*}-C_{C}\right)^{2}+4 K C_{A}^{*}\left(\frac{D_{D}}{D_{C}} C_{B}+\frac{D_{D}}{D_{B}} C_{C}\right)}-\frac{D_{D}}{D_{C}} C_{D}-\frac{D_{D}}{D_{B}} K C_{A}^{*}-C_{C}\right)$ Eq. 16

It confirmed the solution previously determined by Olander (1960) with another mathematical development and this equation is also a solution of the method of Astarita and Savage (1980) $[16,17]$. Indeed, in this case, Eq. 14 is a second degree polynomial equation whose the positive root injected in Eq. 13 leads to Eq. 16. Consequently, whereas the mathematical developments are different between these studies, the analytical solutions are identical.

\subsubsection{Particular case of the recombination with $\mathrm{HO}^{-}$or $\mathrm{H}^{+}: \gamma_{A}=\gamma_{B}=\gamma_{C}=1$ and $\gamma_{D}=0$}

Eqs. 8 and 9 lead to Eq. 17 and Eqs. 11 and 17 to Eq. 18:

$$
\begin{aligned}
& E=\frac{1-C_{A} / C_{A}^{*}+\frac{D_{B}}{D_{A}}\left(\frac{C_{B}-C_{B}^{*}}{C_{A}^{*}}\right)}{1-C_{A} / C_{A}^{*}}=1+\frac{D_{B}}{D_{A}} \frac{C_{B}-C_{B}^{*}}{C_{A}^{*}-C_{A}} \\
& E=\frac{1+\frac{D_{C}}{D_{A}} K\left(C_{B}^{*}+C_{A} \frac{C_{B}^{*}-C_{B}}{C_{A}^{*}-C_{A}}\left(1-1 / \cosh \left(\sqrt{M_{2}}\right)\right)\right)}{1+\frac{D_{C}}{D_{A}} K C_{B}^{*} \tanh \left(\sqrt{M_{2}}\right) / \sqrt{M_{2}}} \text { with } M_{2}=\frac{D_{A} k_{7}}{k_{L}^{2}}\left(C_{B}^{*}+\frac{D_{A}}{K D_{C}}\right)
\end{aligned}
$$

Only Eqs. 17-18 are necessary to determine E by a simple numerical resolution (Fig. 1). For an instantaneous reaction, i.e large values of $\mathrm{M}_{2}$, Eqs. 17 and 18 leads to Eq. 19: 


$$
E_{\infty}=1+\frac{D_{B} C_{B}}{\frac{D_{A} D_{B}}{K D_{C}}+D_{A} C_{A}^{*}}
$$

This equation is identical to the one previously found by Olander (1960) and is also the solution of the system of equations developed by Astarita and Savage $[16,17]$.

\subsubsection{Particular case of dissociation and hydrolysis: $\gamma_{A}=\gamma_{C}=\gamma_{D}=1$ and $\gamma_{B}=0$}

In this case, Eq. 11 leads to Eq. 20 which still needs to be solved numerically using Eqs. 8 and 10:

$$
E=\frac{1+\frac{D_{C}}{D_{A}} \frac{K}{C_{D}^{*}}+\frac{D_{C}}{D_{A}}\left(\frac{K}{C_{D}^{*}} C_{A}-C_{C}\right) \frac{1-1 / \cosh \left(\sqrt{M_{2}}\right)}{C_{A}^{*}-C_{A}}}{1+\frac{D_{C}}{D_{A}} \frac{K}{C_{D}^{*}} \tanh \left(\sqrt{M_{2}}\right) / \sqrt{M_{2}}} \text { with } M_{2}=\frac{D_{A} k_{7}}{k_{L}^{2}}\left(1+\frac{D_{A}}{D_{C}} \frac{C_{D}^{*}}{K}\right)
$$

For an instantaneous reaction, it comes from Astarita and Savage (1980):

$$
\frac{C_{A}^{*}}{C_{A}}=\left(1+\frac{D_{A} \xi}{D_{C} C_{C}}\right)\left(1+\frac{D_{A} \xi}{D_{D} C_{D}}\right)
$$

This equation is a second degree polynomial equation. Determination of the positive root leads to:

$$
E_{\infty}=1+\frac{\sqrt{\left(D_{D} C_{D}+D_{C} C_{C}\right)^{2}-4\left(1-C_{A}^{*} / C_{A}\right)\left(D_{D} C_{D} D_{C} C_{C}\right)}-\left(D_{D} C_{D}+D_{C} C_{C}\right)}{2 D_{A}\left(C_{A}^{*}-C_{A}\right)}
$$

This equation was also determined by Chang and Rochelle with different assumptions (1982).

Table 1 presents all the reactions investigated in this article with the method of calculation of $K$, concentrations and $\mathrm{E}$. 
Table 1 : Synthesis of the different reactions investigated and of the equilibrium constant, the concentrations and $\mathrm{E}$

calculations.

\begin{tabular}{|c|c|c|c|c|}
\hline $\begin{array}{l}\text { Type of } \\
\text { reaction }\end{array}$ & Chemical equation & $\begin{array}{l}\text { Equilibrium constant } \\
\mathrm{K}\end{array}$ & Concentrations & Determination of $\mathrm{E}$ \\
\hline Dissociation & $\begin{array}{l}\text { Eq. 23: } A \rightleftharpoons C+D \\
\text { Example, Eq. } 24: \\
\mathrm{H}_{2} \mathrm{~S} \rightleftharpoons \mathrm{HS}^{-}+\mathrm{H}^{+}\end{array}$ & $\begin{array}{l}\text { Eq. 25: } \\
K_{A}=10^{-p K_{A}}=\frac{C_{C} C_{D}}{C_{A}}\end{array}$ & \multirow{2}{*}{$\begin{array}{l}\text { Eq. 26: } \\
C_{A}=\frac{C_{A}^{\text {Total }}}{1+10^{p H-p K_{A}}} \\
C_{B}=\left[H O^{-}\right]=10^{p H-p K_{e}} \\
C_{C}=\frac{C_{A}^{\text {Total }}}{1+10^{p K_{A}-p H}} \\
C_{D}=\left[H^{+}\right]=10^{-p H}\end{array}$} & $\begin{array}{l}\text { E: Eqs. } 8,9 \text { and } 20 \\
\text { (procedure in Fig. 1) } \\
\text { E }_{\infty} \text { : Eq. } 22\end{array}$ \\
\hline $\begin{array}{l}\text { Recombination } \\
\text { with } \mathrm{HO}^{-}\end{array}$ & $\begin{array}{l}\text { Eq. 27: } \\
A+B \rightleftharpoons C+\mathrm{H}_{2} \mathrm{O} \\
\text { Example, Eq. 28: } \\
\mathrm{H}_{2} \mathrm{~S}+\mathrm{HO}^{-} \rightleftharpoons \mathrm{HS}^{-}+\mathrm{H}_{2} \mathrm{O}\end{array}$ & $\begin{array}{l}\text { Eq. 29: } \\
\frac{K_{A}}{K_{e}}=10^{-p K_{A}+p K_{e}}=\frac{C_{C}}{C_{A} C_{B}}\end{array}$ & & $\begin{array}{l}\text { E: Eqs. } 17 \text { and } 18 \\
\text { (procedure in Fig. 1) } \\
\text { E }_{\infty} \text { : Eq. } 19\end{array}$ \\
\hline $\begin{array}{l}\text { Recombination } \\
\text { with } \mathrm{H}^{+} \\
\text {(protonation) }\end{array}$ & $\begin{array}{l}\text { Eq. 30: } \\
A+B \rightleftharpoons C \\
\text { Example, Eq. 31: } \\
\mathrm{NH}_{3}+\mathrm{H}^{+} \rightleftharpoons \mathrm{NH}_{4}^{+}\end{array}$ & $\begin{array}{l}\text { Eq. 32: } \\
\frac{1}{K_{A}}=10^{p K_{A}}=\frac{C_{C}}{C_{A} C_{B}}\end{array}$ & \multirow{2}{*}{$\begin{array}{l}\text { Eq. 33: } \\
\begin{array}{l}C_{A}=\frac{C_{A}^{\text {Total }}}{1+10^{p K_{A}-p H}} \\
C_{B}=\left[H^{+}\right]=10^{-p H} \\
C_{C}=\frac{C_{A}^{\text {Total }}}{1+10^{p H-p K_{A}}} \\
C_{D}=\left[H O^{-}\right]=10^{p H-p K_{e}}\end{array}\end{array}$} & $\begin{array}{l}\text { E: Eqs. } 17 \text { and } 18 \\
\text { (procedure in Fig. 1) } \\
\text { E }_{\infty} \text { : Eq. } 19\end{array}$ \\
\hline Hydrolysis & $\begin{array}{l}\text { Eq. 34: } \\
A+\mathrm{H}_{2} \mathrm{O} \rightleftharpoons \mathrm{C}+D \\
\text { Example, Eq. 35: } \\
\mathrm{NH}_{3}+\mathrm{H}_{2} \mathrm{O} \rightleftharpoons \mathrm{NH}_{4}^{+}+\mathrm{HO}^{-}\end{array}$ & $\begin{array}{l}\text { Eq. 36: } \\
\frac{K_{e}}{K_{A}}=10^{p K_{A}-p K_{e}}=\frac{C_{C} C_{D}}{C_{A}}\end{array}$ & & $\begin{array}{l}\text { E: Eqs. } 8,9 \text { and } 20 \\
\text { (procedure in Fig. 1) } \\
E_{\infty}: \text { Eq. } 22\end{array}$ \\
\hline $\begin{array}{l}\text { Acid reaction } \\
\text { with a base }\end{array}$ & $\begin{array}{l}\text { Eq. 37: } \\
A+B \rightleftharpoons C+D \\
\text { Example, Eq. 38: } \\
\mathrm{H}_{2} \mathrm{~S}+\mathrm{HCO}_{3}^{-} \rightleftharpoons \mathrm{HS}^{-}+\mathrm{H}_{2} \mathrm{CO}_{3}\end{array}$ & $\begin{array}{l}\mathrm{pK}_{\mathrm{A}}: \mathrm{pK}_{\mathrm{A}} \text { of } \mathrm{A} / \mathrm{C} \\
\mathrm{pK_{A } ^ { \prime }}: \mathrm{pK}_{\mathrm{A}} \text { of } \mathrm{D} / \mathrm{B} \\
\mathrm{Eq} \cdot 39: \\
\frac{K_{A}}{K_{A}^{\prime}}=10^{p K_{A}^{\prime}-p K_{A}}\end{array}$ & $\begin{array}{l}\text { Eq. 40: } \\
C_{A}=\frac{C_{A}^{\text {Total }}}{1+10^{p H-p K_{A}}} \\
C_{B}=\frac{C_{B}^{\text {Total }}}{1+10^{p K_{A}{ }^{\prime}-p H}} \\
C_{C}=\frac{C_{A}^{\text {Total }}}{1+10^{p K_{A}-p H}} \\
C_{D}=\frac{C_{B}^{\text {Total }}}{1+10^{p H-p K_{A}}}\end{array}$ & $\begin{array}{l}\text { E: Eqs. 8,9,10 and } 15 \\
\text { (procedure in Fig. 1) } \\
\text { E }_{\infty} \text { : Eq. } 16\end{array}$ \\
\hline $\begin{array}{l}\text { Base reaction } \\
\text { with an acid }\end{array}$ & $\begin{array}{l}\text { Eq. 41: } \\
A+B \rightleftharpoons C+D \\
\text { Example, Eq. 42: } \\
\mathrm{NH}_{3}+\mathrm{HCO}_{3}^{-} \rightleftharpoons \mathrm{NH}_{4}^{+}+\mathrm{CO}_{3}^{2-}\end{array}$ & $\begin{array}{l}\mathrm{pK}_{\mathrm{A}}: \mathrm{pK}_{\mathrm{A}} \text { of } \mathrm{C} / \mathrm{A} \\
\mathrm{pK}_{\mathrm{A}}^{\prime}: \mathrm{pK}_{\mathrm{A}} \text { of } \mathrm{B} / \mathrm{D} \\
\mathrm{Eq} \cdot 43: \\
\frac{K_{A}^{\prime}}{K_{A}}=10^{p K_{A}-p K_{A}^{\prime}}\end{array}$ & $\begin{array}{l}\text { Eq. 44: } \\
C_{A}=\frac{C_{A}^{\text {Total }}}{1+10^{p K_{A}-p H}} \\
C_{B}=\frac{C_{B}^{\text {Total }}}{1+10^{p H-p K_{A}{ }^{\prime}}} \\
C_{C}=\frac{C_{A}^{\text {Total }}}{1+10^{p H-p K_{A}}} \\
C_{D}=\frac{C_{B}^{\text {Total }}}{1+10^{p K_{A}{ }^{\prime}-p H}}\end{array}$ & 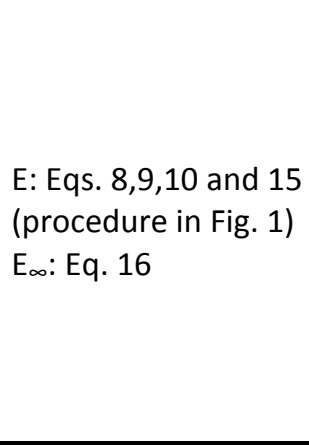 \\
\hline
\end{tabular}




\section{Results and discussion}

\subsection{Introduction}

Table 2: Presentation of the various scenarii investigated.

\begin{tabular}{|c|c|c|c|c|c|c|}
\hline \multicolumn{7}{|c|}{ Operating conditions } \\
\hline $\mathrm{T}=293.15 \mathrm{~K}$ & \multicolumn{2}{|c|}{$\mathrm{k}_{\mathrm{L}}=10^{-4} \mathrm{~m} \cdot \mathrm{s}^{-1}$} & \multicolumn{2}{|c|}{$\mathrm{k}_{\mathrm{G}}=10^{-2} \mathrm{~m} \cdot \mathrm{s}^{-1}$} & \multicolumn{2}{|c|}{$L / G=3.5$} \\
\hline \multicolumn{7}{|c|}{$\mathrm{H}_{2} \mathrm{~S}$ and $\mathrm{CH}_{3} \mathrm{SH}$ studies } \\
\hline \multirow{3}{*}{ Description } & Scen & rio 1 & Scenario 2 & Scen & io 3 & Scenario 4 \\
\hline & \multicolumn{3}{|c|}{ High value of $C_{A}^{G}$} & \multicolumn{3}{|c|}{ Low value of $C_{A}^{G}$} \\
\hline & \multicolumn{2}{|c|}{$E f f=0.05$} & $E f f=0.001$ & \multicolumn{2}{|c|}{$E f f=0.05$} & $\mathrm{Eff}=0.001$ \\
\hline$C_{A}^{G}\left(m g \cdot m^{-3}\right)$ & \multicolumn{3}{|c|}{100} & \multicolumn{3}{|c|}{1} \\
\hline $\mathrm{C}_{\mathrm{A}}^{*}\left(\mathrm{~mol} \cdot \mathrm{L}^{-1}\right)$ & \multicolumn{3}{|c|}{$8.1 \times 10^{-6}\left(\mathrm{H}_{2} \mathrm{~S}\right) / 1.11 \times 10^{-5}\left(\mathrm{CH}_{3} \mathrm{SH}\right)$} & \multicolumn{3}{|c|}{$8.1 \times 10^{-7}\left(\mathrm{H}_{2} \mathrm{~S}\right) / 1.11 \times 10^{-7}\left(\mathrm{CH}_{3} \mathrm{SH}\right)$} \\
\hline $\mathrm{C}_{\mathrm{A}}^{\text {Total }}\left(\mathrm{mg} \cdot \mathrm{L}^{-1}\right)$ & \multicolumn{2}{|c|}{1.7} & 0.034 & \multicolumn{2}{|c|}{0.017} & 0.00034 \\
\hline $\mathrm{C}_{\mathrm{A}}^{\text {Total }}\left(\mathrm{mol} . \mathrm{L}^{-1}\right)$ & \multicolumn{2}{|c|}{$\begin{array}{c}5.1 \times 10^{-5}\left(\mathrm{H}_{2} \mathrm{~S}\right) \\
3.6 \times 10^{-5}\left(\mathrm{CH}_{3} \mathrm{SH}\right) \\
\end{array}$} & $\begin{array}{c}1.0 \times 10^{-6}\left(\mathrm{H}_{2} \mathrm{~S}\right) \\
7.2 \times 10^{-7}\left(\mathrm{CH}_{3} \mathrm{SH}\right) \\
\end{array}$ & \multicolumn{2}{|c|}{$\begin{array}{c}5.1 \times 10^{-7}\left(\mathrm{H}_{2} \mathrm{~S}\right) \\
3.6 \times 10^{-7}\left(\mathrm{CH}_{3} \mathrm{SH}\right)\end{array}$} & $\begin{array}{c}1.0 \times 10^{-8}\left(\mathrm{H}_{2} \mathrm{~S}\right) \\
7.2 \times 10^{-9}\left(\mathrm{CH}_{3} \mathrm{SH}\right)\end{array}$ \\
\hline \multicolumn{7}{|c|}{$\mathrm{NH}_{3}$ study } \\
\hline \multirow{3}{*}{ Description } & Scenario 1 & Scenario 2 & Scenario 3 & Scenario 4 & Scenario 5 & Scenario 6 \\
\hline & \multicolumn{2}{|c|}{ High value of $C_{A}^{G}$} & \multicolumn{2}{|c|}{ Medium value of $C_{A}^{G}$} & \multicolumn{2}{|c|}{ Low value of $C_{A}^{G}$} \\
\hline & $\mathrm{Eff}=0.9$ & $\mathrm{Eff}=0.05$ & $\mathrm{Eff}=0.9$ & $E f f=0.05$ & $\mathrm{Eff}=0.9$ & $\mathrm{Eff}=0.05$ \\
\hline$C_{A}^{G}\left(m g \cdot m^{-3}\right)$ & \multicolumn{2}{|c|}{100} & \multicolumn{2}{|c|}{1} & \multicolumn{2}{|c|}{0.01} \\
\hline $\mathrm{C}_{\mathrm{A}}^{*}\left(\mathrm{~mol} . \mathrm{L}^{-1}\right)$ & \multicolumn{2}{|c|}{$5.6 \times 10^{-4}$} & \multicolumn{2}{|c|}{$5.6 \times 10^{-6}$} & \multicolumn{2}{|c|}{$5.6 \times 10^{-8}$} \\
\hline $\mathrm{C}_{\mathrm{A}}^{\text {Total }}\left(\mathrm{mg} \cdot \mathrm{L}^{-1}\right)$ & 31.0 & 1.7 & 0.31 & 0.017 & 0.0031 & 0.00017 \\
\hline $\mathrm{C}_{\mathrm{A}}^{\text {Total }}\left(\mathrm{mol} . \mathrm{L}^{-1}\right)$ & $1.82 \times 10^{-3}$ & $1.01 \times 10^{-4}$ & $1.82 \times 10^{-5}$ & $1.01 \times 10^{-6}$ & $1.82 \times 10^{-7}$ & $1.01 \times 10^{-8}$ \\
\hline
\end{tabular}

Table 3 : Values of the diffusion coefficients at infinite dilution, $\mathrm{pK}_{\mathrm{A}}$ and Henry's law constant in water used for the simulations (293.15 K).

\begin{tabular}{|c|c|c|c|c|}
\hline Compound & $\mathrm{pK}_{\mathrm{A}}$ & 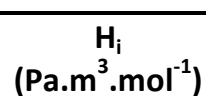 & $\begin{array}{l}10^{9} D_{i} \\
\left(m^{2} \cdot s^{-1}\right)\end{array}$ & $\begin{array}{l}\text { Reference or } \\
\text { method for } D_{i}\end{array}$ \\
\hline Free $\mathrm{HO}^{-}$ & \multirow{2}{*}{$\mathrm{pK}_{\mathrm{e}}=14.15$} & & 5.17 & Self-diffusivity [15] \\
\hline Free $\mathrm{H}^{+}$ & & & 9.16 & Self-diffusivity [15] \\
\hline $\mathrm{NaOH}$ & Strong base & & 2.09 & Nernst-Haskell [27] \\
\hline $\mathrm{H}_{2} \mathrm{SO}_{4}$ & Strong acid & & 3.41 & Nernst-Haskell [27] \\
\hline $\mathrm{H}_{2} \mathrm{~S}$ & \multirow{2}{*}{7.08 [29] } & $864[41]$ & 1.75 & [47] \\
\hline Free $\mathrm{HS}^{-}$ & & & 1.75 & Approximation \\
\hline $\mathrm{CH}_{3} \mathrm{SH}$ & \multirow{2}{*}{10.33} & $430[29]$ & 1.26 & [29] \\
\hline Free $\mathrm{CH}_{3} \mathrm{~S}^{-}$ & & & 1.26 & Approximation \\
\hline $\mathrm{NH}_{3}$ & \multirow{2}{*}{9.37 [48] } & $1.36[48]$ & 1.51 & [49] \\
\hline Free $\mathrm{NH}_{4}^{+}$ & & & 1.92 & Self-diffusivity [15] \\
\hline $\mathrm{H}_{2} \mathrm{CO}_{3}$ & \multirow{3}{*}{$\begin{array}{c}6.47 / 10.38 \\
{[29]}\end{array}$} & & 1.80 & [50] \\
\hline $\mathrm{HCO}_{3}{ }^{-}$ & & & 0.966 & [50] \\
\hline $\mathrm{CO}_{3}^{-}$ & & & 0.707 & [50] \\
\hline
\end{tabular}


E determination can be achieved depending on $C_{A}^{*}$ (which depends mainly on $C_{A}^{G}$ and $H_{A}$ and more or less on $k_{L}, k_{G}, E$ ) and $C_{A}^{\text {Total }}$. Therefore, to assess the influence of $C_{A}^{*}$ and $C_{A}$ on the enhancement factor, simulations are performed for 4 scenarii for $\mathrm{H}_{2} \mathrm{~S}$ and $\mathrm{CH}_{3} \mathrm{SH}$ and 6 scenarii for $\mathrm{NH}_{3}$ (Table 2). These scenarii corresponds to several cases of figure. For all scenarii, $C_{A}^{*}$ is deduced from fixed values of $C_{A}^{G}$ using Eq. 4 with $E=1$ and assuming $C_{A} \ll C_{A}^{*}$. In a volume element of the liquid phase, $C_{A}^{\text {Total }}$ depends on the liquid flow pattern, the configuration (co-current or counter-current), the gas and liquid flow rates and the removal efficiency already reached in this element. $C_{A}^{\text {Total }}$ is deduced from the amount transferred for a given removal efficiency Eff (which ensures that $C_{A}^{*}>C_{A}$ whatever the simulated $\mathrm{pH}$ ), a given gas phase concentration $C_{A}^{G}$, and a gas-to-liquid mass flow rate ratio $L / G$ of 3.5 (classical value in packed columns):

$C_{A}^{\text {Total }}=\frac{\rho_{G}}{\rho_{L} L / G} E f f \times C_{A}^{G}$

Simulations are performed for various $\mathrm{pH}$. It requires the values of the diffusion coefficients of each compound (Table 3). These values are considered constant in the liquid film and are determined assuming an infinite dilution [5]. Special considerations arise for the determination of ionic species diffusion coefficients. For ionic species and electrolytes ( $\mathrm{NaOH}$ or $\mathrm{H}_{2} \mathrm{SO}_{4}$ added to set the $\mathrm{pH}$ ), if the coefficients do not exist in the literature, calculations are performed using the Nernst-Haskell equations for electrolytes $\left(\mathrm{NaOH}, \mathrm{H}_{2} \mathrm{SO}_{4}\right.$, etc.) and the relation cited by Danckwerts for free ions $\left(\mathrm{H}^{+}\right.$ or $\mathrm{HO}^{-}$for example) which require the ions conductivity $\lambda\left(\mathrm{S} \cdot \mathrm{mol}^{-1} \cdot \mathrm{m}^{-2}\right)[5,15,27,31]$ :

$D_{\mathrm{i}^{+} \sim \mathrm{i}}=\frac{R T}{F^{2}} \frac{z_{i^{+}}+z_{i^{-}}}{z_{i^{+}} \times z_{i^{-}}} \frac{\lambda_{i^{+}} \times \lambda_{i^{-}}}{\lambda_{i^{+}}+\lambda_{i^{-}}}$with $\mathrm{F}$ the faraday constant and $\mathrm{z}$ the electrical charge of $\mathrm{i}^{+}$or $\mathrm{i}^{-} \quad$ Eq. 46 $D_{\mathrm{i}^{+}}=\frac{R T}{F^{2}} \frac{\lambda_{i^{+}}}{z_{i^{+}}}$and $D_{i^{-}}=\frac{R T}{F^{2}} \frac{\lambda_{i^{-}}}{z_{i^{-}}}$

$\mathrm{H}^{+}$and $\mathrm{HO}^{-}$free ions diffuse 2 or 3 times faster than the corresponding electrolytes (Table 3). When $\mathrm{H}^{+}$and $\mathrm{HO}^{-}$are provided by an electrolyte ( $\mathrm{NaOH}$ and $\mathrm{H}_{2} \mathrm{SO}_{4}$ for example) in sufficient amounts, Eq. 46 is used to determine effective $\mathrm{HO}^{-}$and $\mathrm{H}^{+}$diffusion coefficients since the condition of electrical neutrality requires that $\mathrm{HO}^{-}$or $\mathrm{H}^{+}$diffuse at the same rate than their counterions $\left(\mathrm{HO}^{-}\right.$and $\mathrm{H}^{+}$are slowed down whereas the counterions are sped up) [15,32]. When $\mathrm{HO}^{-}$and $\mathrm{H}^{+}$are provided by pure water, free ion diffusion coefficients should be used since the conditions of electrical neutrality is respected. Between this two limit cases (for example natural water or water containing a small amount of acid or base to slightly change the $\mathrm{pH}$ ), the choice of the diffusion coefficients of the ionic 
species is a critical issue. On the contrary, when $\mathrm{H}^{+}$or $\mathrm{HO}^{-}$are released in pure water (for example when $\mathrm{H}_{2} \mathrm{~S}_{\mathrm{G}} \rightleftharpoons \mathrm{HS}^{-}+\mathrm{H}^{+}$), electrical neutrality requires that counterions ( $\mathrm{HS}^{-}$in this example), $\mathrm{H}^{+}$and $\mathrm{HO}^{-}$ diffuse at the same rate [32]. In this case, the $\mathrm{H}^{+} / \mathrm{HO}^{-}$and counterions diffusion coefficients are calculated using Eq. 46. When an extraneous electrolyte is added to the water ( $\mathrm{NaCl}$ for example), if sufficient relative excess of any salt is distributed uniform concentration throughout the system, the effective diffusion coefficients of $\mathrm{H}^{+}$and $\mathrm{HO}^{-}$which are released are the free ions diffusion coefficients [15,32]. Assuming in this article that in any case, electrolytes are added to set the $\mathrm{pH}$, in order to simplify the simulation and considering that it will not change with a great extent the conclusions, the free ions diffusion coefficients are chosen for the ions released and the effective conductivity calculated with Eq. 46 are chosen for the reacting ions. We recommend to anyone to adapt to his own conditions (pure water, natural water containing buffers such as carbonates, process water doped with $\mathrm{NaOH}$ or $\mathrm{H}_{2} \mathrm{SO}_{4}$, etc.).

Unfortunately, for $\mathrm{HS}^{-}$and $\mathrm{CH}_{3} \mathrm{~S}^{-}$, the molar conductivity and diffusion coefficient has not been found in the literature. Therefore, we considered the free ion diffusion coefficients equal to the molecular diffusion coefficient of $\mathrm{H}_{2} \mathrm{~S}$ and $\mathrm{CH}_{3} \mathrm{SH}$ since the diffusion of small molecule in water do not vary widely as mentioned by Danckwerts [15].

The simulation requires also the knowledge of at least the reverse or the forward kinetics constant. However, the reactions are extremely fast and therefore these values are poorly known. One of the goal of this article is to prove that this ignorance is not always determinant since the assumption of an instantaneous reversible reaction can provide a good estimation of the enhancement factor in many cases.

\subsection{Absorption of an acid in pure water doped with sodium hydroxide}

When an acid is absorbed in water (in which sodium hydroxide can be added to set an alkaline $\mathrm{pH}$ ), potentially two reactions are possible: dissociation or recombination with $\mathrm{HO}$. For $\mathrm{H}_{2} \mathrm{~S}$, these reactions are respectively Eqs. 24 and 28. For dissociation reactions, the forward kinetic constant is usually very high $\left(10^{10}\right.$ to $\left.10^{11} \mathrm{~L}^{\mathrm{mol}} \mathrm{m}^{-1} . \mathrm{s}^{-1}\right)$ [18]. For $\mathrm{H}_{2} \mathrm{~S}$, the reverse kinetic constant $\mathrm{k}_{-24}$ is equal to $7.5 \times 10^{10} \mathrm{~L} \mathrm{~mol}^{-1} \cdot \mathrm{s}^{-1}$ [18]. Therefore, the forward kinetic constant $\mathrm{k}_{24}$ is equal to $10^{-\mathrm{pK}_{\mathrm{A}} \times \mathrm{K}_{-24}}=6.24 \times 10^{3}$ $\mathrm{s}^{-1}$ with $\mathrm{pK}_{\mathrm{A}}=7.08$ at $293 \mathrm{~K}$ [29]. For reaction 28 , both forward and reverse kinetic constants are unknown. However, the order of magnitude of a recombination reaction with $\mathrm{HO}^{-}$is expected between $10^{9}$ and $10^{11} \mathrm{~L}$. mol ${ }^{-1} \cdot \mathrm{s}^{-1}$ [18]. Consequently, for the recombination with $\mathrm{HO}^{-}$reaction, different simulations will be presented with varying values of $k_{28}$ in this range. We note that the 
simulation has been extended to acidic $\mathrm{pH}$ (which would require to set the $\mathrm{pH}$ with an acid more than with $\mathrm{NaOH}$ ) since even at such $\mathrm{pH}, \mathrm{E}$ values larger than 1 are calculated.

\subsubsection{Study of the dissociation reaction}

Fig. 2 presents the evolution of $\mathrm{E}$ due to the dissociation reaction vs. the $\mathrm{pH}$ for the 4 scenarii (Table 2). The first and probably the most important conclusion is that the dissociation reaction does not enable to reach large values of $E$ and consequently to increase very significantly the absorption rate. It means that dissociation on the liquid film remains marginal by comparison to the recombination with $\mathrm{HO}^{-}$except for $\mathrm{pH}<9$ where both reactions can participate to the process ( $\S 3.2 .2$ ). The enhancement depends predominantly on $\mathrm{C}_{\mathrm{A}}{ }^{*}$ the $\mathrm{pH}$ and the total concentration of $\mathrm{H}_{2} \mathrm{~S}$ in solution. From a global point of view, $E$ is higher when $C_{A}{ }^{*}$ and $C_{A}^{\text {Total }}$ decrease at a given $\mathrm{pH}$. E stays constant for $\mathrm{pH}>\mathrm{pK}_{\mathrm{A}}+2$. Even at $\mathrm{pH}$ lower than the $\mathrm{pK}_{\mathrm{A}}(7.08)$, which means that $\mathrm{H}_{2} \mathrm{~S}$ is predominant over $\mathrm{HS}^{-}$, a small enhancement exists. Another important conclusion is that $E$ is equal to $E_{\infty}$ except for extreme $\mathrm{pH}$ where the deviation is lower than $3 \%$ for scenarii 3 and 4 . It means that at low $\mathrm{pH}$, the process is totally controlled by the equilibrium while at high $\mathrm{pH}$, the reaction kinetics can have a small influence.

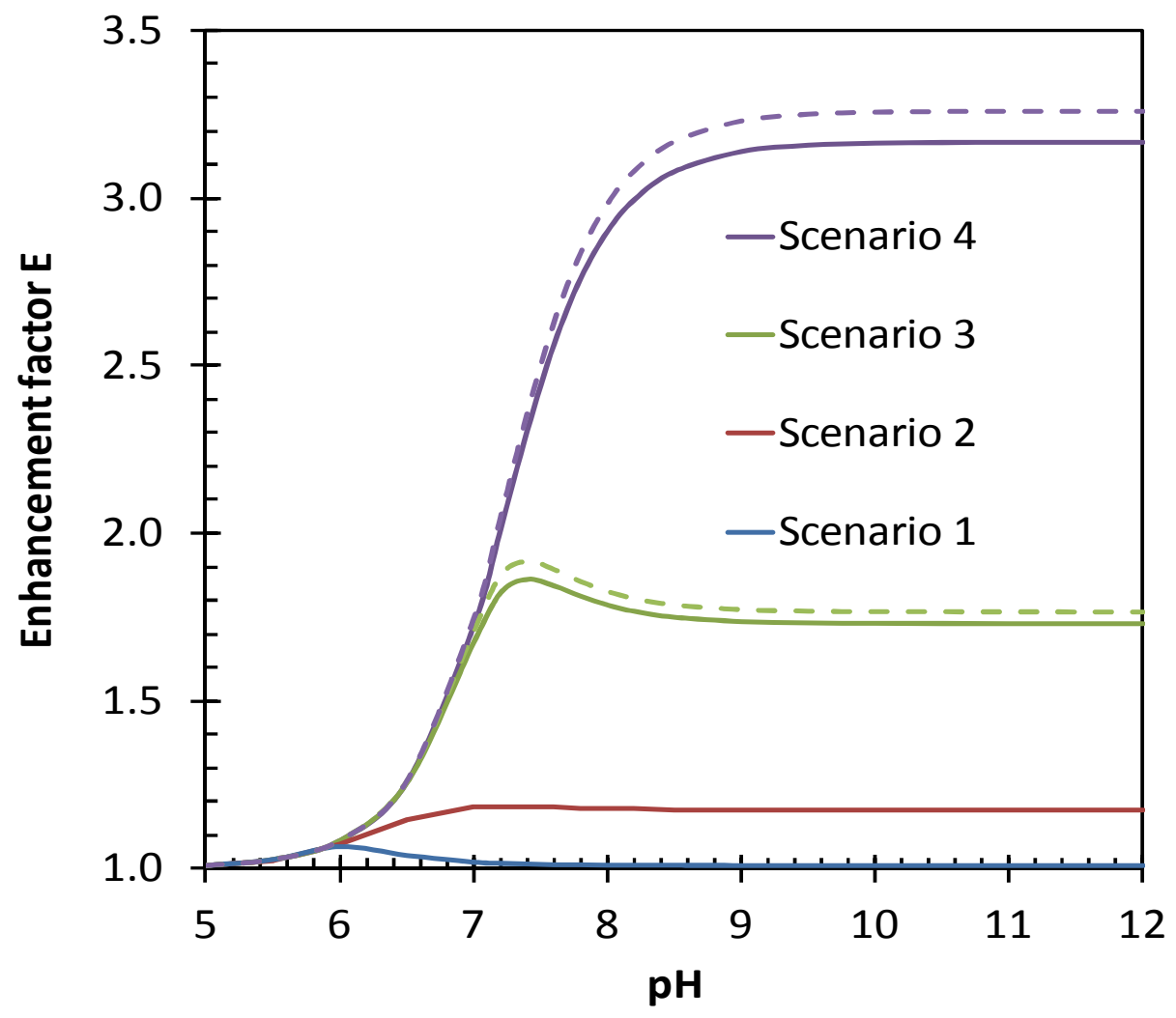

Figure 2 : Evolution of $\mathrm{E}$ vs. the $\mathrm{pH}$ due to the $\mathrm{H}_{2} \mathrm{~S}$ dissociation reaction for scenarii 1 to $4\left(\mathrm{~K}=8.32 \times 10^{-8} \mathrm{~mol} . \mathrm{L}^{-1}\right)$. Dash lines correspond to E $\infty$. 
For $\mathrm{CH}_{3} \mathrm{SH}\left(\mathrm{K}=1.66 \times 10^{-5}\right.$ mol. $\left.\mathrm{L}^{-1}\right)$, the maximal values of $\mathrm{E}_{\infty}\left(\mathrm{E}_{\infty}=1.05\right)$ are obtained for scenario 4 at $\mathrm{pH}$ 9.5-10 showing that this reaction is not significant. It means that dissociation reaction has an influence only for strong acid or acid whose $\mathrm{pK}_{\mathrm{A}}$ remains lower than 7-8.

\subsubsection{Study of the recombination with HO- reaction}

Fig. 3 presents the evolution of $\mathrm{E}$ due to the recombination with $\mathrm{HO}^{-}$for scenarii 1 and 3 vs. the $\mathrm{pH}$ for different values of $k_{28}$. The results of scenarii 2 and 4 are not presented since they are identical to the results of respectively scenarii 1 and 3 which means that in this case, $C_{A}$ has no influence. The first important conclusion is that, contrary to the dissociation reaction, recombination with $\mathrm{HO}^{-}$ reaction enables to reach large values of $E$ for alkaline $\mathrm{pH}$. The increasing amount of reactant $\left(\mathrm{HO}^{-}\right)$ with the $\mathrm{pH}$ improves the influence of this reaction. For scenarii 1 and 2, the ignorance of the kinetic constant is not problematic except for extreme $\mathrm{pH}$ since the values found with different values of $\mathrm{k}_{28}$ are equal at low $\mathrm{pH}$. Furthermore, for higher $\mathrm{pH}$, the enhancement factor is so high that its calculation is not required anymore. Indeed, according to Eq. 6 , as soon as E $>320$, only $10 \%$ of the total resistance for mass transfer is located in the liquid film ( $\mathrm{E}>680$ for $5 \%$ ). Therefore, the absorption rate depends on a limited extent on $E$ for $E>320$ and can be approximated by neglecting the liquid resistance with a low error. Consequently, designers can determine with a low uncertainty the enhancement factor with the assumption that the reaction is instantaneous when the kinetic constant cannot be found in the literature. For low values of $C_{A}^{*}$ (in the top of a scrubber operating at counter-current), this assumption should be considered carefully depending on the true value of $k_{28}$. A value of $k_{28}$ close to $3.0 \times 10^{10} \mathrm{~L} . \mathrm{mol}^{-1} . \mathrm{s}^{-1}$ can be expected in many cases for acid recombination with $\mathrm{HO}^{-}$and can be used in the computation [51]. To maximize the absorption rate, a pH larger than 1011 will be required. For $\mathrm{pH}>10.5$, the absorption rate increasing with the $\mathrm{pH}$ is less sensitive since the $E$ values are so large that the liquid resistance is almost negligible. This conclusion is in accordance with the results reported by Chen et al. (2001) [6].

For the $\mathrm{CH}_{3} \mathrm{SH}$ recombination with $\mathrm{HO}^{-}$, the simulation is done with a kinetics constant $=3.0 \times 10^{10}$ L.mol ${ }^{-1} \cdot \mathrm{s}^{-1}$. Due to a higher $\mathrm{pK}_{\mathrm{A}}$, it is necessary to increase the $\mathrm{pH}$ to at least 11-11.5 (Fig. 4) to reach interesting $E$ values $(E=5.56$ for $\mathrm{pH}=11)$. The difference between scenarii $1-2$ and $3-4$ is rather small and the results are close to those obtained considering an instantaneous reaction. 

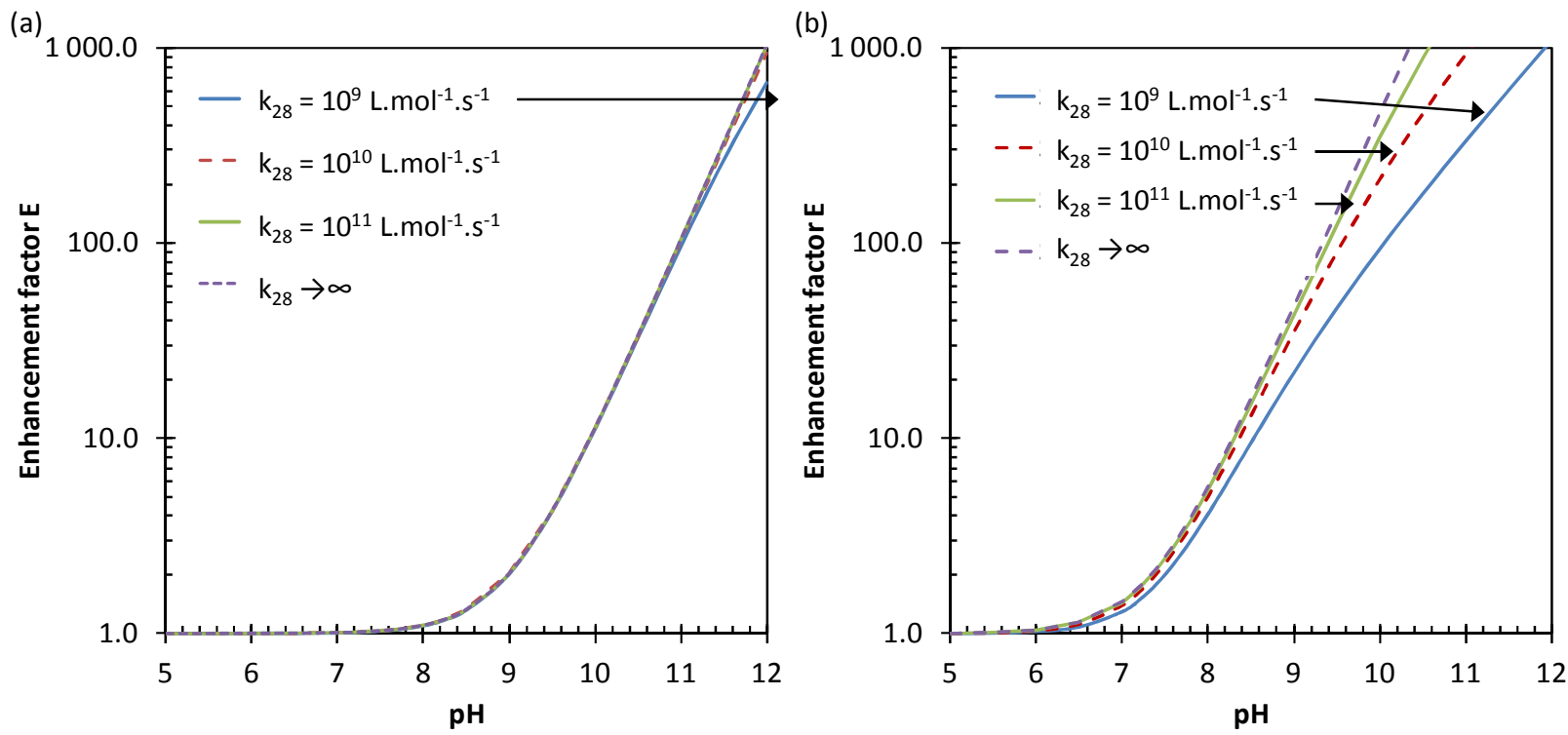

Figure 3 : (a) Evolution of the expected E vs. the pH due to the $\mathrm{H}_{2} \mathrm{~S}$ recombination reaction for scenarii 1 and 2 for different values of $k_{28}$. (b) Evolution of the expected $\mathrm{E}$ vs. the $\mathrm{pH}$ due to the $\mathrm{H}_{2} \mathrm{~S}$ recombination reaction for scenarii 3 and 4 for different values of $k_{28}\left(K=1.18 \times 10^{7} \mathrm{~L} \mathrm{~mol}^{-1}\right)$.

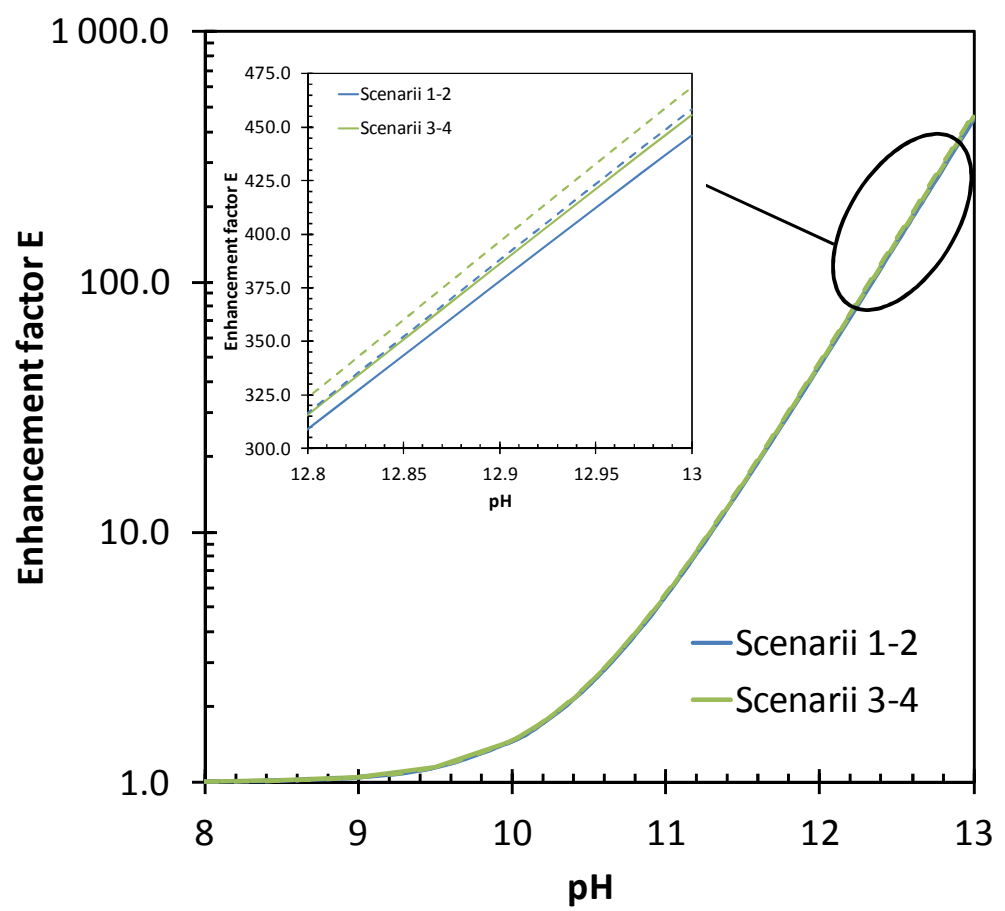

Figure 4 : Evolution of the expected $\mathrm{E}$ vs. the $\mathrm{pH}$ due to the $\mathrm{CH}_{3} \mathrm{SH}$ recombination reaction $\left(\mathrm{K}=6.64 \times 10^{3} \mathrm{~L}\right.$. $\left.\mathrm{mol}^{-1}\right)$. Dash lines correspond to $\mathrm{E} \infty$. 


\subsubsection{Influence of alkaline species}

Previous results (3.2.1 and 3.2.2) were calculated by considering that the scrubbing liquid was composed of pure water and sodium hydroxide. However, process water contains compounds which can interact in the process, especially $\mathrm{CO}_{3}{ }^{2-}, \mathrm{HCO}_{3}{ }^{-}$and $\mathrm{H}_{2} \mathrm{CO}_{3}$ which are the main buffers in the system. The main issue dealing with proton transfer reactions between two different acid-base pairs in water is the ignorance of the kinetic constant. As mentioned by Eigen (1964), there are relationships between the rate constant for proton transfer and $\mathrm{pK}_{\mathrm{A}}$ difference (noted $\Delta \mathrm{pK}_{\mathrm{A}}$ ) between the donor (acid) and the acceptor (base) [18]. $\mathrm{CO}_{3}{ }^{2-}$ and $\mathrm{HCO}_{3}{ }^{-}$are potentially two acceptors with respective $\Delta \mathrm{pK}_{\mathrm{A}}$ equal to -3.30 and 0.61 at $293.15 \mathrm{~K}$. For many inorganic acid-base pairs, for $\Delta \mathrm{pK}_{\mathrm{A}}$ $=-3.30(0.61)$ the $\log \left(k_{\text {forward }}\right)$ is in the order of magnitude 9.5-10 (8-8.5) which leads to $k_{\text {forward }}$ of at least $1.0 \times 10^{8}$ for the reaction between $\mathrm{H}_{2} \mathrm{~S}$ and $\mathrm{CO}_{3}{ }^{2-}\left(3.6 \times 10^{9} \mathrm{~L}^{-\mathrm{mol}^{-1}} \cdot \mathrm{s}^{-1}\right.$ for the reaction between $\mathrm{H}_{2} \mathrm{~S}$ and $\mathrm{HCO}_{3}{ }^{-}$).
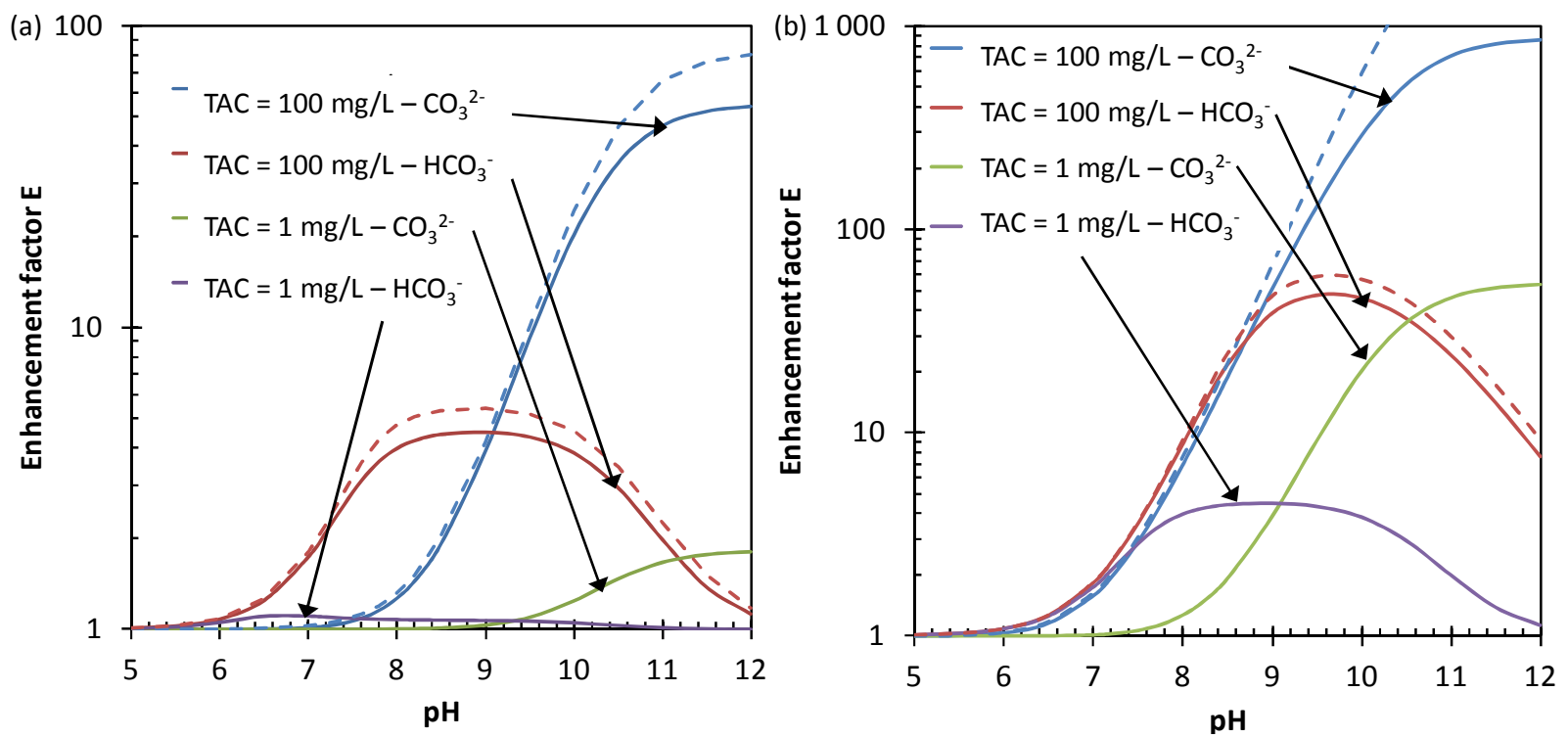

Figure 5 : (a) Evolution of the expected E vs. the $\mathrm{pH}$ due to the reaction with $\mathrm{CO}_{3}{ }^{2-}$ and $\mathrm{HCO}_{3}{ }^{-}$for scenarii 1 for TAC $=100$ and $1 \mathrm{mg} / \mathrm{L}$. (b) Evolution of the expected $\mathrm{E}$ vs. the $\mathrm{pH}$ due to the reaction with $\mathrm{CO}_{3}{ }^{2-}$ and $\mathrm{HCO}_{3}{ }^{-}$for scenarii 3 for TAC = 100 and $1 \mathrm{mg} / \mathrm{L}$. (K with $\mathrm{CO}_{3}{ }^{2-}=2.02 \times 10^{3}$ and $\mathrm{K}$ with $\mathrm{HCO}_{3}{ }^{-}=2.43 \times 10^{-1}$ ). Dash lines correspond to $\mathrm{E} \infty$.

Simulations are performed for scenarii 1 and 3 for a high value (TAC $=100 \mathrm{mg}$ of $\mathrm{CO}_{2} / \mathrm{L}$ ) and for a low value $\left(\mathrm{TAC}=1 \mathrm{mg}\right.$ of $\mathrm{CO}_{2} / \mathrm{L}$ ) of the total alkalinity (Fig. 5). The main conclusion is that parasite reactions with $\mathrm{CO}_{3}{ }^{2-}$ and $\mathrm{HCO}_{3}{ }^{-}$can play an evident role in the global enhancement of $\mathrm{H}_{2} \mathrm{~S}$ transfer. This is obviously the case when the TAC is large. Reaction with $\mathrm{HCO}_{3}{ }^{-}$is more significant at circumneutral $\mathrm{pH}$ and the reaction with $\mathrm{CO}_{3}{ }^{2-}$ is more significant at high $\mathrm{pH}$ in their respective predominance domains. The enhancement due to these parasite reactions is particularly significant for low $C_{A}{ }^{*}$. We note that in many cases, $E$ is close to $E_{\infty}$. To really assess the potential of 
enhancement of these reactions, a global enhancement factor should be calculated taking into account at the same time these reactions and the reaction with $\mathrm{HO}^{-}$and the dissociation. This calculation can be solved with a complicated numerical resolution taking into account the differential equations relative to material balances of each species and all the reactions possible between them. To simplify, when all the reaction can be considered as instantaneous, the overall enhancement factor can be deduced from the sum of the individual enhancement factors [7].

\subsection{Absorption of a base in pure water doped with sulfuric acid}

When a base is absorbed in water (in which an acid such as sulfuric acid can be added to set an acid $\mathrm{pH})$, two reactions are potentially possible: protonation or hydrolysis. For $\mathrm{NH}_{3}$, these reactions are Eqs. 31 and 35. For protonation reaction, the forward kinetic constant is very large $\left(10^{10}\right.$ to $10^{11}$ L.mol ${ }^{-1} \cdot \mathrm{s}^{-1}$ for many bases) and for ammonia $\mathrm{k}_{31}=4.310^{10} \mathrm{~L} \cdot \mathrm{mol}^{-1} \cdot \mathrm{s}^{-1}[18]$. For the hydrolysis reaction, $\mathrm{k}_{-35}$ is equal to $3.410^{10} \mathrm{~L} \cdot \mathrm{mol}^{-1} \cdot \mathrm{s}^{-1}[18]$. Therefore, the forward kinetic constant $\mathrm{k}_{35}$ is equal to $10^{-\mathrm{pk}_{\mathrm{A}} \times \mathrm{k}}$. $35=5.6510^{5} \mathrm{~s}^{-1}$ with $\mathrm{pK}_{\mathrm{A}}=9.37$ at $293 \mathrm{~K}$ [48]. We note that the simulation has been extended to basic $\mathrm{pH}$ (which would require to set the $\mathrm{pH}$ with a base more than with an acid) since values of $\mathrm{E}$ larger than 1 are calculated.

Fig. 6 demonstrates that the protonation reaction enable to reach larger values of $E$ than the hydrolysis except for $\mathrm{pH}$ close to the neutrality where both reactions must be considered. The behavior is close to the one obtained with $\mathrm{H}_{2} \mathrm{~S}$. Indeed, in both cases, the enhancement factor increases when $C_{A}^{*}$ decreases. For relatively high values of $C_{A}^{*}$ (scenarii 1 to 4 ), $E$ is equal to $E_{\infty}$ which means that the process is controlled by the equilibrium and not the kinetics (i.e the reaction is instantaneous). Consequently, Eq. 17 can be used to determine the enhancement factor very easily. Moreover, while:

$\frac{D_{B}}{K D_{C}} \ll C_{A}^{*} \Rightarrow C_{A}^{*} \gg \frac{3.41}{1.92 \times 10^{-p K_{A}}}=7.5 \times 10^{-10} \mathrm{~mol} / \mathrm{L}$

$E$ is equal to:

$$
E=1+\frac{D_{B}}{D_{A}} \frac{C_{B}}{C_{A}^{*}}
$$

This equation is the same than for an instantaneous irreversible bimolecular reaction [29]. It means than in this case, the reverse reaction is negligible compared to the forward reaction, contrary to the case of $\mathrm{H}_{2} \mathrm{~S}$ reaction with $\mathrm{HO}^{-}$. Consequently, the assumption of an irreversible instantaneous reaction must be avoided. For low values of $C_{A}^{*}$ (scenarii 5 and 6 ), there is a deviation between $E$ and 
$\mathrm{E}_{\infty}$ which varies from $1 \%$ at $\mathrm{pH} 9$ to $98 \%$ at $\mathrm{pH} 2$. Ammonia is highly soluble in water with a low Henry's constant (Table 3 ). When $E=1$, only $5 \%$ of the mass transfer resistance is located in the liquid phase $(1 \%$ when $E=6)$. Therefore, for ammonia, a low enhancement is required to maximize the absorption rate.

For the hydrolysis reaction, the enhancement factor is constant except near the $\mathrm{pK}_{\mathrm{A}}$ (Fig. $5 \mathrm{~b}$ ). $\mathrm{E}$ increases as expected when $C_{A}^{*}$ decreases but is almost independent of $C_{A}^{\text {Total }}$ for low values of $C_{A}^{*}$ (scenarii 5-6).
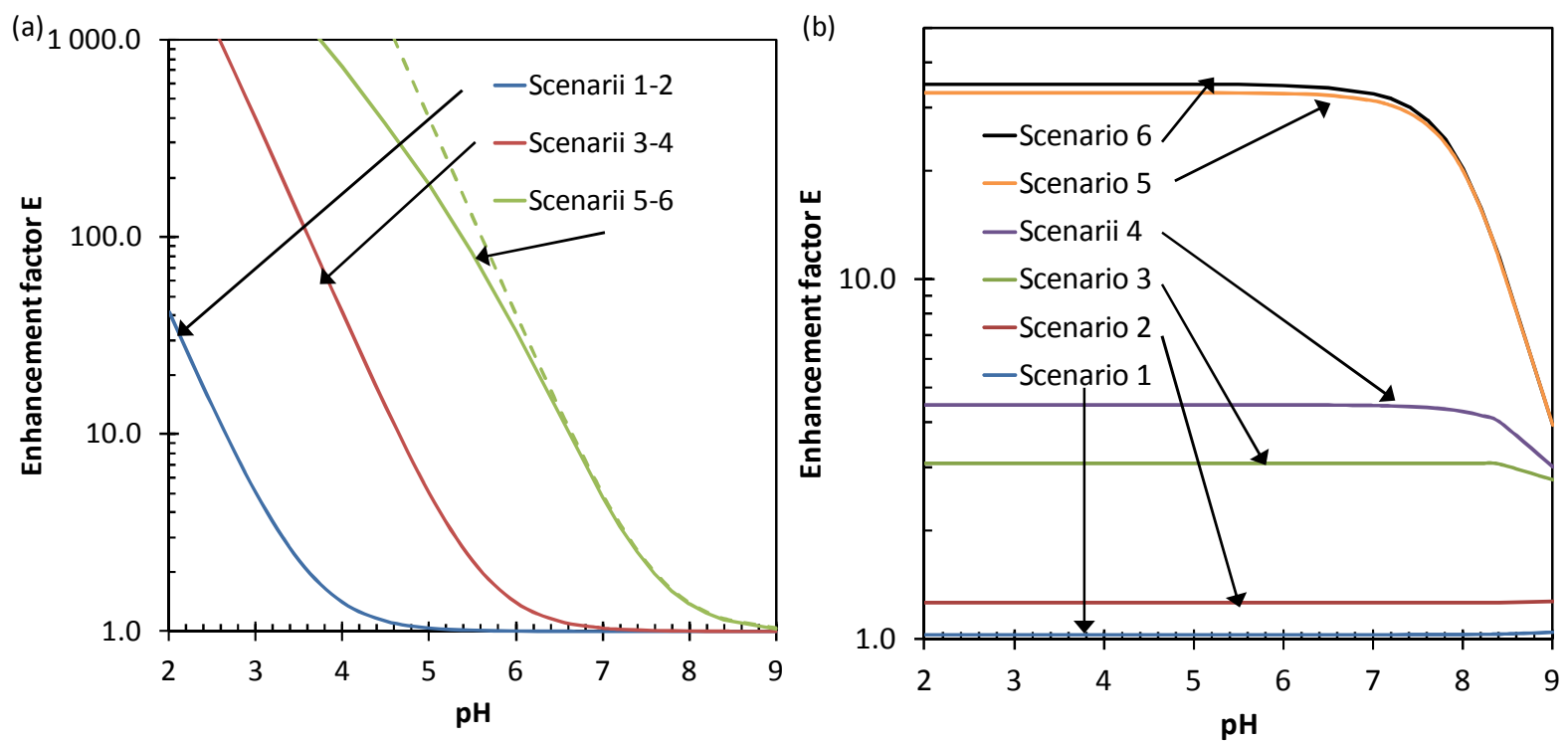

Figure 6: (a) Evolution of $\mathrm{E}$ vs. the $\mathrm{pH}$ due to the $\mathrm{NH}_{3}$ protonation reaction for scenarii 1 to $6\left(\mathrm{~K}=2.36 \times 10^{9} \mathrm{~L}\right.$.mol $\left.{ }^{-1}\right)$. (b) Evolution of $\mathrm{E}$ vs. the $\mathrm{pH}$ due to the $\mathrm{NH}_{3}$ hydrolysis reaction for scenarii 1 to $6\left(\mathrm{~K}=1.66 \times 10^{-5} \mathrm{~mol} . \mathrm{L}^{-1}\right)$. The dashed lines correspond to $\mathrm{E}_{\infty}$. 


\section{Conclusions}

This article gives an overview of mass transfer enhancement factor determination for acidic and basic compounds transfer in water. This enhancement results from reversible acid-base reactions in the liquid film (dissociation, protonation, hydrolysis and recombination with $\mathrm{HO}^{-}$). The main conclusions are:

- Usually, E increases when $C_{A}^{*}$ decreases.

- Influence of these reactions increases when the $\mathrm{pK}_{\mathrm{A}}$ decreases (increases) for an acid (a base).

- The enhancement factor due to monomolecular reactions (dissociation, hydrolysis) has an asymptotic behavior. It is significant only for acidic (basic) compounds with a $\mathrm{pK}_{\mathrm{A}}$ close or lower (larger) than 7.Since the reactions involved are really fast, in some cases, they can be assumed instantaneous. In this case, analytical equations are usable, making the enhancement factor determination easier. However, they must not be considered as irreversible assuming that the reverse reactions is negligible.

- When the reaction is not instantaneous compared to mass transfer rate, the reaction kinetics must be considered. In this case, a simple numerical resolution is required to solve the set of Eqs. 8-11 following the procedure reported in Fig. 1. A solver such as the Excel ${ }^{\circledR}$ solver can be used without restriction.

- Even if the reaction is not instantaneous, this approximation can leads to rather low deviations especially when the $\mathrm{pH}$ is close to the $\mathrm{pK}_{\mathrm{A}}$. Usually, the deviations increased for $\mathrm{pH}$ far from the $\mathrm{pK}_{\mathrm{A}}$ whith large enhancement factor. In this case, the liquid resistance could be low. It means that in this case the absorption rate depends poorly on $\mathrm{E}$, i.e. a rather large deviation of $\mathrm{E}$ have a small influence on the gas-liquid contactor design.

- The assumption of an instantaneous reaction can be necessary to avoid a numerical resolution and/or if the kinetic constant is unknown. In this case, one should confirm that this assumption does not lead to a large uncertainty by trying to compare $E_{\infty}$ and $E$ obtained with a low but realistic value of the kinetics constant (Fig. 3b).

- For acidic (basic) compounds, at alkaline (acidic) $\mathrm{pH}$, the enhancement is mainly due to the recombination with $\mathrm{HO}^{-}$(protonation) reaction. In these cases, $\mathrm{E}$ is significantly influenced by the $\mathrm{pH}$ and $\mathrm{C}_{\mathrm{A}}{ }^{*}$.

- Usually, one reaction can be neglected comparing to the other one for a large $\mathrm{pH}$ range. This conclusion is not completely true at circumneutral $\mathrm{pH}$. However, in many cases, both reversible reactions can be considered as instantaneous and it becomes possible to calculate the total enhancement factor with the sum of the individual ones [7].If natural water is used, alkalinity 
$\left(\mathrm{CO}_{3}{ }^{2-}, \mathrm{HCO}_{3}{ }^{-}\right.$and $\left.\mathrm{H}_{2} \mathrm{CO}_{3}\right)$ must be considered. Nevertheless, in industrial processes, it would be interesting to demineralize the process water to limit the buffer power and decrease the consumption of acid and soda necessary to set the $\mathrm{pH}$. 


\section{References}

[1] F.I. Khan, A.K. Ghoshal, Removal of Volatile Organic Compounds from polluted air, J. Loss Prev. Proc. Ind., 13 (2000) 527-545.

[2] G. Busca, P. Chiara, Technologies for the abatement of sulphide compounds from gaseous streams: a comparative overview, J. Loss Prev. Proc. Ind., 16 (2003) 363-371.

[3] G. Busca, P. Chiara, Abatement of ammonia and amines from waste gases : a summary, J. Loss Prev. Proc. Ind., 16 (2003) 157-163.

[4] Ö. Yildirim, A.A. Kiss, N. Hüser, K. Leßmann, E.Y. Kenig, Reactive absorption in chemical process industry: A review on current activities, Chem. Eng. J., 213 (2012) 371-391.

[5] R.H. Perry, D.W. Green, Perry's chemical engineers' handbook, $7^{\text {th }}$ edition, McGraw-Hill, NewYork, 1997.

[6] L. Chen, J. Huang, C.-L. Yang, Absorption of $\mathrm{H}_{2} \mathrm{~S}$ in $\mathrm{NaOCl}$ caustic aqueous solution, Environ. Prog., 20 (2001) 175-181.

[7] W.P.M. van Swaaij, G.F. Versteeg, Mass transfer accompanied with complex reversible chemical reactions in gas-liquid systems: an overview, Chem. Eng. Sci., 47 (1992) 3181-3195.

[8] P.-F. Biard, A. Couvert, C. Renner, J.-P. Levasseur, Wet scrubbing intensification applied to hydrogen sulphide removal in waste water treatment plant, Can. J. Chem. Eng., 88 (2010) 682-687.

[9] F. Larachi, M. Cassanello, A. Laurent, Gas-liquid interfacial mass transfer in trickle-bed reactors at elevated pressures, Ind. Eng. Chem. Res., 37 (1998) 718-733.

[10] A. Gonzalez-Sanchez, S. Revah, M.A. Deshusses, Alkaline biofiltration of $\mathrm{H}_{2} \mathrm{~S}$ odors, Environ. Sci. Technol., 42 (2008) 7398-7404.

[11] O. Brettschneider, R. Thiele, R. Faber, H. Thielert, G. Wozny, Experimental investigation and simulation of the chemical absorption in a packed column for the system $\mathrm{NH}_{3}-\mathrm{CO}_{2}-\mathrm{H}_{2} \mathrm{~S}-\mathrm{NaOH}-\mathrm{H}_{2} \mathrm{O}$, Sep. Pur. Technol., 39 (2004) 139-159.

[12] D.W. Van Krevelen, P.J. Hoftijzer, Kinetics of gas-liquid reactions. Part I. General Theory, Rec. Trav. Chim. Pays-Bas, 67 (1948) 563-586.

[13] W.G. Whitman, A preliminary experimental confirmation of the two-film theory of gas absorption, Chem. Met. Eng., 29 (1923) 146-148.

[14] G.F. Versteeg, J.A.M. Kuipers, F.P.H. Van Beckum, W.P.M. Van Swaaij, Mass transfer with complex reversible chemical reactions-I. Single reversible chemical reaction, Chem. Eng. Sci., 44 (1989) 2295-2310.

[15] P.V. Danckwerts, Gas absorption with instantaneous reaction, Chem. Eng. Sci., 23 (1968) 10451051. 
[16] D.R. Olander, Simultaneous mass transfer and equilibrium chemical reaction, AIChE Journal, 6 (1960) 233-239.

[17] G. Astarita, D.W. Savage, Gas absorption and desorption with reversible instantaneous chemical reaction, Chem. Eng. Sci., 35 (1980) 1755-1764.

[18] M. Eigen, Proton transfer, acid-base catalysis, and enzymatic hydrolysis. Part I: elementary processes, Angewandte Chem. Int. Edition in English, 3 (1964) 1-19.

[19] K. Onda, E. Sada, T. Kobayashi, M. Fujine, Gas absorption accompanied by complex chemical reactions- I Reversible chemical reactions, Chem. Eng. Sci., 25 (1970) 753-760.

[20] H. Hikita, S. Asai, Gas absorption with $(m, n)^{\text {th }}$ order irreversible chemical reaction, Int. Chem. Eng., 4 (1964) 332-340.

[21] E. Kenig, A. Górak, A film model based approach for simulation of multicomponent reactive separation, Chem. Eng. Proc.: Proc. Int., 34 (1995) 97-103.

[22] E.Y. Kenig, U. Wiesner, A. Górak, Modeling of reactive absorption using the Maxwell-Stefan equations, Ind. Eng. Chem. Res., 36 (1997) 4325-4334.

[23] R. Schneider, E. Kenig, A. Gorak, Dynamic modelling of reactive absorption with the MaxwellStefan approach, Chem. Eng. Res. Des., 77 (1999) 633-638.

[24] C. Noeres, E. Kenig, A. Gorak, Modelling of reactive separation processes: reactive absorption and reactive distillation, Chem. Eng. Proc.: Proc. Int., 42 (2003) 157-178.

[25] E.Y. Kenig, L. Kucka, A. Górak, Rigorous modeling of reactive absorption processes, Chem. Eng. Technol., 26 (2003) 631-646.

[26] G.F. Versteeg, J.A.M. Kuipers, F.P.H. Van Beckum, W.P.M. Van Swaaij, Mass transfer with complex reversible chemical reactions-II. parallel reversible chemical reactions, Chem. Eng. Sci., 45 (1990) 183-197.

[27] C.S. Chang, G.T. Rochelle, $\mathrm{SO}_{2}$ absorption into $\mathrm{NaOH}$ and $\mathrm{Na}_{2} \mathrm{SO}_{3}$ aqueous solutions, Ind. Eng. Chem. Fund., 24 (1985) 7-11.

[28] C.S. Chang, G.T. Rochelle, Mass transfer enhanced by equilibrium reactions, Ind. Eng. Chem. Fund., 21 (1982) 379-385.

[29] M. Roustan, Transferts gaz-liquide dans les procédés de traitement des eaux et des effluents gazeux, Lavoisier, Paris, 2003.

[30] J. Coca, J.L. Bueno, R. Alvarez, Gaseous diffusion coefficients by the Stefan-Winkelmann method using a polymer-solvent mixture as evaporation source, Ind. Eng. Chem. Fund., 19 (1980) 219-221.

[31] R. Reid, T. Sherwood, The properties of gases and liquids - Chapter 11, Chemical Engineering Series, (1966) 646.

[32] C.S. Chang, G.T. Rochelle, $\mathrm{SO}_{2}$ absorption into aqueous solutions, AIChE Journal, 27 (1981) $292-$ 298. 
[33] D.A. Glasscock, G.T. Rochelle, Numerical simulation of theories for gas absorption with chemical reaction, AIChE Journal, 35 (1989) 1271-1281.

[34] R.J. Littel, B. Filmer, G.F. Versteeg, W.P.M. Van Swaaij, Modelling of simultaneous absorption of $\mathrm{H}_{2} \mathrm{~S}$ and $\mathrm{CO}_{2}$ in alkanolamine solutions: The influence of parallel and consecutive reversible reactions and the coupled diffusion of ionic species, Chem. Eng. Sci., 46 (1991) 2303-2313.

[35] C. Bonnin, Les sources de nuisances olfactives dans les stations de traitement des eaux usées résiduaires, et leur traitement par lavage à l'eau chlorée en milieu basique, PhD Thesis of Université de Rennes I, Rennes, 1991, pp. 191.

[36] R. Sander, Compilation of Henry's law constants for inorganic and organic species of potential importance in environmental chemistry, in: Max-Planck Institute of Chemistry, Mainz, Germany, 1999.

[37] J. Xia, Á. Pérez-Salado Kamps, B. Rumpf, G. Maurer, Solubility of $\mathrm{H}_{2} \mathrm{~S}$ in $\left(\mathrm{H}_{2} \mathrm{O}+\mathrm{CH}_{3} \mathrm{COONa}\right)$ and $\left(\mathrm{H}_{2} \mathrm{O}+\mathrm{CH}_{3} \mathrm{COONH}_{4}\right)$ from 313 to $393 \mathrm{~K}$ and at pressures up to $10 \mathrm{MPa}$, J. Chem. Eng. Data, 45 (2000) 194-201.

[38] M.C. Iliuta, F. Larachi, Solubility of total reduced sulfurs (Hydrogen sulfide, Methyl mercaptan, Dimethyl sulfide, and Dimethyl disulfide) in Liquids, J. Chem. Eng. Data, 52 (2006) 2-19.

[39] J. Altschuh, R. Brüggemann, H. Santl, G. Eichinger, O.G. Piringer, Henry's law constants for a diverse set of organic chemicals: Experimental determination and comparison of estimation methods, Chemosphere, 39 (1999) 1871-1887.

[40] T.J. Barrett, G.M. Anderson, J. Lugowski, The solubility of hydrogen sulphide in $0-5 \mathrm{~m} \mathrm{NaCl}$ solutions at $25^{\circ}-95^{\circ} \mathrm{C}$ and one atmosphere, Geochim. Cosmochim. Acta, 52 (1988) 807-811.

[41] R. Fernández-Prini, J.L. Alvarez, A.H. Harvey, Henry's constants and vapor-liquid distribution constants for gaseous solutes in $\mathrm{H}_{2} \mathrm{O}$ and $\mathrm{D}_{2} \mathrm{O}$ at high temperatures, J. Phys. Chem. Ref. Data, 32 (2003) 903-916.

[42] S.-T. Lin, S.I. Sandler, Henry's law constant of organic compounds in water from a group contribution model with multipole corrections, Chem. Eng. Sci., 57 (2002) 2727-2733.

[43] A.V. Plyasunov, E.L. Shock, Prediction of the vapor-liquid distribution constants for volatile nonelectrolytes in water up to its critical temperature, Geochim. Cosmochim. Acta, 67 (2003) 49815009.

[44] J. Vorholz, B. Rumpf, G. Maurer, Prediction of the vapor-liquid phase equilibrium of hydrogen sulfide and the binary system water-hydrogen sulfide by molecular simulation, Phys. Chem. Chem. Phys., 4 (2002) 4449-4457.

[45] Z. Duan, N. Møller, J.H. Weare, Prediction of the solubility of $\mathrm{H}_{2} \mathrm{~S}$ in $\mathrm{NaCl}$ aqueous solution: an equation of state approach, Chem. Geol., 130 (1996) 15-20. 
[46] A. Lara Marquez, G. Wild, N. Midoux, A review of recent chemical techniques for the determination of the volumetric mass-transfer coefficient $\mathrm{k}_{\mathrm{L}} \mathrm{a}$ in gas-liquid reactor, Chem. Eng. Proc., 33 (1994) 247-260.

[47] A. Tamimi, E.B. Rinker, O.C. Sandall, Diffusion coefficients for hydrogen sulfide, carbon dioxide, and nitrous oxide in water over the temperature range 293-368 K, J. Chem. Eng. Data, 39 (1994) 330332.

[48] K. Kawazuishi, J.M. Prausnitz, Correlation of vapor-liquid equilibria for the system ammoniacarbon dioxide-water, Ind. Eng. Chem. Res., 26 (1987) 1482-1485.

[49] M.J.W. Frank, J.A.M. Kuipers, W.P.M. van Swaaij, Diffusion coefficients and viscosities of $\mathrm{CO}_{2}+$ $\mathrm{H}_{2} \mathrm{O}, \mathrm{CO}_{2}+\mathrm{CH}_{3} \mathrm{OH}, \mathrm{NH}_{3}+\mathrm{H}_{2} \mathrm{O}$, and $\mathrm{NH}_{3}+\mathrm{CH}_{3} \mathrm{OH}$ liquid mixtures, J. Chem. Eng. Data, 41 (1996) 297302.

[50] R.E. Zeebe, On the molecular diffusion coefficients of dissolved $\mathrm{CO}_{2}, \mathrm{HCO}_{3}{ }^{-}$, and $\mathrm{CO}_{3}{ }^{2-}$ and their dependence on isotopic mass, Geochim. Cosmochim. Acta, 75 (2011) 2483-2498.

[51] M.C. Rose, J. Stuehr, Kinetics of proton transfer reactions in aqueous solution. III. Rates of internally hydrogen-bonded systems, J. Am. Chem. Soc., 90 (1968) 7205-7209. 